(Aus dem physiologischen Institut der Universität Jena.)

\title{
Beiträge zur vergleichenden Physiologie der Verdauung.
}

\author{
IV. \\ Die Verdaunng und der Verdannngsapparat des Flusskrebses \\ (Astacus fluviatilis). \\ Von \\ Dr. phil. H. Jordan, \\ Privatdocent an der Universität Zürich.
}

(Mit 6 Textfiguren und Tafel VII.)

\section{Die „Leber" des Krebses und ihr Secret.}

Ueber die Verdauung des Krebses liegen schon eine ganze Reihe z. Th. vortrefflicher Arbeiten vor, und es sind daher meine folgenden Mittheilungen im Wesentlichen ergänzende und berichtigende. Besondere Mühe habe ich darauf verwendet, den merkwürdig complicirten Mechanismus aufzuklären, durch welchen die gelösten Verdauungsproducte aus dem Magen in die hier, wie bei den Mollusken, als wichtigstes Resorptionsorgan fungirende "Leber" befördert werden. Eine "physiologische Anatomie" des Krebsmagens darf ich als das Hauptziel der vorliegenden Untersuchungen bezeichnen.

Hinsichtlich des Grundplanes im Bau des Verdauungsapparates besteht im Wesentlichen Uebereinstimmung bei allen Arthropoden. Schon Huxley gliedert in seinem inhaltreichen Buche über den "Krebs" den Verdaungstract im Vorder-, Mittel- und Enddarm, von denen der erstere, sowie der letztere einen dicken Cuticularüberzug besitzen, der besonders im sogenannten Kaumagen ausserordentlich entwickelt ist, während der, wenigstens bei den Dekapoden, sehr kurze Mitteldarm wie bei den Insecten eines solchen Ueberzuges gänzlich entbehrt.

„Der Mund führt beim Flusskrebs (Astacus fl.), (den wir als den physiologisch am genauesten untersuchten Repräsentanten der 
Crustaceen als Typus wählen wollen) in eine verhältnissmässig weite, aber kurze Röhre, den Schlund (Fig. bei Cori \& Hatschek, Zootomie), der beinahe senkrecht zur Rückenfläche emporsteigt und den Magen bildet, indem er sich plötzlich zu einem abgerundeten Sacke erweitert. Beim Austritt aus dem Magen nimmt der Darm wiederum ein röhrenförmiges Aussehen an, und indem er auf der ganzen Strecke beinahe die gleiche Dicke, ausser am Endtheile, wo er sich etwas erweitert, beibehält, geht er in gerader Linie nach binten." "Der Magen (Kaumagen) ist innerlich durch eine starke Querfalte in zwei Kammern eingetheilt, wovon die vordere, in welche der Schlund (Oesophagus) mündet, die Cardiaka m mer genannt werden kann, während die bedeutend engere hintere Abtheilung die sogenannte Pförtnerkammer bildet. Die ganze innere Magenfläche ist, wie die des Schlundes, mit einer Chitinlamelle überzogen, welche die Fortsetzung der nach innen eingestülpten Chitinschicht des Teguments ist. Die Chitinschicht des Magens verdickt sich stellenweise ungemein, kann sogar verkalken und eine Anzahl von Skelettstücken hervorbringen, welche zum Kauen und Zerreiben der Nahrungsstoffe dienen." Unter dem Namen "Magenmühle" schildert $\mathrm{Huxley}$ ausführlich dieses Magenskelett, für welches eine Analogie im Kaumagen vieler Insekten, sowie in gewissem Sinne in dem complicirten Mund-Kauapparat der Echiniden (Laterne des Aristoteles) besteht. „Wenn man den Vordertheil der Cardiakammer öffnet, sieht man an der Hinterfläche mehrere Zähne erscheinen, welche in der Höhlung vorspringen. Sie werden durch gegliederte und auf einander verschiebbare Chitinlamellen getragen. Auf der äusseren Fläche dieser Lamellen setzen sich Muskeln an, welche die Aufgabe haben, sie in Bewegung zu setzen, die Zähne von einander zu entfernen oder zu nähern, so dass der Mageninhalt von Innen gefasst und zerrissen wird" (Vogt und Y ung, vergl. Anat. Bd. II S. 36 und Fig. 17). Könnten noch Zweifel geäussert werden hinsichtlich der physiologischen Bedeutung des Proventrieulus (Kaumagens) der Insekten, so dürfte das wohl kaum denkbar sein bezüglich des Kaumagens der Crustaceen, und in der That sind die mechanischen Leistungen desselben nicht zu unterschätzen.

Dicht an den Pylorustheil des Magens setzt sich die enge Röhre des Mitteldarmes an. Sie ist bei den meisten Decopoden äusserst kurz und misst selbst bei grossen Thieren nur einige Millimeter. „Dem Mitteldarm sind zwei Systeme von Anbangsorganen 
eigen, deren erstes die Mitteldarmdrüse (Leber) umfasst. Diese Drüse, in doppelter Zahl vorhanden, mündet mit je einem Ausführungsgang vorne ventral ein und zwar direct hinter dem Pylorusmagen, an einer Stelle, wo das Cylinderepithel des Mitteldarmes schon aufhört und die Cuticularbekleidung des Vorderdarmes sichtbar wird. Sie ist räumlich ungemein entwickelt und liefert die zur Verdauung nöthigen Enzyme. Zwar ist sie als Ausstülpung des Mitteldarmes zu betrachten, besitzt aber andere Epithelzellen als dieser. Das zweite System von Anhangsorganen ist von untergeordneter Bedeutung, indem es räumlich meist nur wenig entwickelt ist.

Diese Anhänge, welche als einfache Aussackungen des Mitteldarmes anzusprechen sind, münden mehr dorsalwärts und am Ende dieses Darmabschnittes ein, dort, wo er in den Enddarm übergeht. Bei Astacus findet sich nur eine unpaare Aussackung (Darmtasche Huxleys). In einzelnen Fällen (D romia, Pachygrapsus) gestalten sich diese Darmanhänge zu zwei langen fadenförmigen Schläuchen.

Ohne weitere Complication geht der Mitteldarm in den Enddarm über, welcher gleichfalls in seiner äusseren Gestaltung höchst einfach ist und den Körper des Thieres der Länge nach in gerader Richtung durchzieht. Er bildet meist den längsten Theil des ganzen Darmtractus und ist gänzlich frei von Anhängen und selbstständig entwickelten Drüsen, während doch bei vielen Arthropoden hier die Malpighischen Gefässe münden. Bisweilen kommen in der Wand des Enddarmes drüsige Gebilde von ganz ähnlicher Beschaffenheit vor, wie sie zuerst M. Braun im Bindegewebe des Oesophagus als ,Speicheldrüsen ${ }^{6}$ beschrieben hat. Vitzou bezeichnete die ersteren als ,Intestinaldrüsen', was, wie Frenzel bemerkt, bei der gänzlichen Unkenntniss der physiologischen Function der Oesophagusdrüsen wohl auch für diese vorläufig als der passendste Ausdruck erscheint. "Allerdings ist ibre histologische Structur ganz die, wie wir sie von eehten Speicheldrüsen kennen, und sollte es sich bewahrheiten, dass auch das von ihnen gelieferte Sekret ein entsprechendes ist, so würden sie wohl am besten als, intestinale Speicheldrüsen" aufzuführen sein" (Frenzel). Am schönsten entwickelt sind sie bei Maja, deren Enddarm sie in erstaunlicher Menge enthält. Sie bilden in der Regel rundliche Acini, von denen oft mehrere zu einem Complex vereinigt sind. Jeder Acinus wird 
von einer Anzahl radiär angeordneter Zellen zusammengesetzt, welche fast bis zum Centrum reichen und bei Maja nur äusserst spärlich, bei Pagurus und Palinurus dagegen dicht gekörnt. erscheinen.

Die stetige Chitinbekleidung (Cuticularisirung) des ganzen langen Enddarmes, welche als Product der cylindrischen Hypodermiszellen (Matrix, chitinogene Membran) aufzufassen ist, lässt im Verein mit dem Drüsenmangel beim Krebs auf eine nur unwesentliche Bedeutung dieses Darmabschnittes für die eigentlichen Verdauungsprocesse schliessen, welche sich daher anscheinend ganz vorwiegend im Magen und Mitteldarm abspielen unter dem Einfluss des Secretes, welches vor Allem die grossen Anhangsdrüsen derselben (der Leber) producieren. „Auf den ersten Blick hin sieht das Epithel des Mitteldarmes dem des Enddarmes nicht unähnlich, da es gleichfalls aus hohen Cylinderzellen besteht. Nur sind die ersteren noch länger gestreckt und überhaupt viel grösser (bei Astacus $120-150 \mu$ Frenzel, Arch. f. m. A. Bd. 25 Taf. IX Fig. 13.) Ein bestimmt geformtes Secret, wie es für das Mitteldarmepithel der Insecten in der Regel so charakteristisch ist, lassen die betreffenden Zellen bei den Crustaceen nur selten und in undeutlicher Weise erkennen. Bei Astacus färbt sich der obere Theil der Zellen stärker mit Hämatoxylin als das übrige feinkörnige Plasma. Bürstenbesätze, welche . bei den entsprechenden Elementen der Insecten oft so riesig entwickelt erscheinen, sind hier kaum angedeutet. Im Mitteldarm von Astacus sieht der Zellsaum wie eine sehr dünne mit Poren versehene Cuticula aus, welche sich hier und da stärker, meist aber schwächer als der Zellinhalt gefärbt erweist. Bei Maja erscheint der Saum nach Sublimatbehandlung deutlich aus einzelnen kräftigen Stäbchen zusammengesetzt.

Die geringe Entwicklung des Mitteldarmes der meisten Crustaceen, sowie der geschilderte Bau der Zellen desselben, machen es an sich höchst wahrscheinlich, dass die Hauptmenge und vielleicht sogar alle Verdaungsenzyme von den kolossal entwickelten ventralen Anhangsdrüsen (Leber) producirt werden, so dass im Gegensatz zu den Insecten der Mitteldarm für die Verdaung sozusagen entbehrlich geworden ist.

Lediglich von morphologischen Gesichtspunkten aus hat man 
seit lange die grosse Mitteldarmdrüse der Crustaceen mit der Leber der Wirbelthiere verglichen und auch immer als solche bezeicknet, obschon einwandfreie physiologische Beweise für eine solche Auffassung nicht geliefert werden konnten. So sprechen Carus, Wagner, Cuvier stets von einer "Leber" und nennen dementsprechend deren Secret "Galle". In gleicher Weise deutet auch Brandt dieses Organ beim Flusskrebs und bei Onisciden. Die Leber des ersteren Dekapoden wurde hierauf in den vierziger Jahren von verschiedenen Forschern eingehend untersucht (Karste $\mathrm{n}$, Schlemm, Meckel, Lereboullet, Frey und Leukart) und stets als solche gewürdigt, wenngleich die Beschaffenheit des Secretes seiner Deutung als "Galle" zu widerstreben schien. Sehr bezeichnend ist die folgende Aeusserung von Schlemm: "Ratio bilis Astaci physica et chemica $a b$ illa animalium vertebratorum adeo differt, ut nisi ex universa organi secernentis natura illud hepar esse satis constaret, facile quis animum induceret, ut secretum aliud quiddam quam bilem esse crederet." So ging diese Deutung der Mitteldarmdrüse auch in die Lehrbücher der hentigen Zeit über, obschon das Fehlen irgendwelcher anderer drüsiger Organe, welche man für die Bildung der Verdauungssäfte hätte verantwortlich machen können, wohl schon frühzeitig auf die Vermuthung hätte führen können, den in Rede stehenden Drüsen neben der immerhin möglichen Bedeutung als "Leber" noch andere Functionen zuzuschreiben. Clau s scheint, wie M. W eber bemerkt (l. c.), unter den Morphologen der erste gewesen zu sein, der begründeten Zweifeln in seiner Schrift über Branchipus und Apus klaren Ausdruck gab: "Sicher werden wir auch bei den Wirbellosen in erster Linie nach Secreten zu suchen haben, welche die Eiweissstoffe in lösliche Modificationen überführen und auch Amylaceen in Zucker umzusetzen vermögen. Bei dem Mangel anderweitiger Drüsen wird daher die Deutung dieser sogenannten Leberschläuche als Drüsen, welche ähnlich wie die Labdrüsen, bezw. die Bauchspeicheldrüsen der Vertebraten wirken, viel grössere Wahrscheinlichkeit haben, als die alte der Bezeichnungsweise entsprechende Auffassung derselben als gallenbereitende Organe. Was wir auf dem Gebiete der Wirbellosen "Leber" nennen, darf, wie mir scheint, durchaus nicht physiologisch mit der Leber der Wirbelthiere verglichen werden, selbst wenn die Farbe des Secretes an Gallensecret erinnert ... Wir sollten daher in dem Gebrauche der Bezeichnung "Leber" auf dem 
Gebiete der Wirbellosen möglichst vorsichtig sein, so lange uns genaue chemische Untersuchungen und physiologische Versuche über die Bedeutung derselben fehlen" (Claus, Zur Kenntniss des Baues und der Entwicklung von Branchipus und Apus. (Ges. d. Wiss. zu Göttingen Bd. 18. 1873.)

„Wie sehr aber diese Vorsicht am Platze ist, haben die Untersuchungen von Hoppe-Seyler, L. Fredericq und Krukenbe rg gezeigt. Aus diesen Untersuchungen geht nämlich hervor, dass die sogenannte Leber der Crustaceen eine Verdau ungsdrüse ist, deren Secret, möchte es sich bei verschiedenen Species auch verschieden verhalten, bald tryptische, bald peptische Eigenschaften hat, ja zuweilen noch saccharificirende oder fettzersetzende, jedenfalls stets fermentirend auf Eiweisskörper einwirkte" (M. Weber). Am einfachsten gestaltet sich der Bau der "Leber" bei den Is opoden. Die Mitteldarmdrüse der Landasseln setzt sich aus vier Blindschläuchen zusammen, die sich gleich hinter dem Kaumagen anheften und dem Darm eng anliegend bis nahe zum After erstrecken. Jeder Schlauch läuft an seinem blinden Ende spitz aus und zeigt einen Farbenton, der zwischen Hellgelb bis Dunkelbraun oder Olivengrün variirt, was theils von der Menge des angesammelten Secretes, theils vom jeweiligen Futterzustand des Thieres, sowie von der Jahreszeit abhängt. Durch circuläre quergestreifte Muskelfasern, welche in geringen Abständen von einander reifenartig die Drüsenschläuche umziehen und durch feinere längsverlaufende Fasern untereinander verbunden sind, so dass ein zierliches Netz entsteht, erscheinen die Schläuche eigenthümlich eingeschnürt und scheinbar spiralig gedreht (M. Weber, l. c. Taf. XXXVI, Fig. 1). Die grosse Bedeutung dieses über der Tunica propria gelegenen Muskelnetzes für die Entleerung der langen, engen Schläuche liegt auf der Hand. Im Gegensatze zu M. Weber, welcher zwei verschiedene Arten von Zellen in den Drüsenschläuchen annahm, gibt es nach J. Frenzel (l. c.) nur eine Art von secretorischen Elementen, welche in zwei Gruppen zerfallen, in grosse, reife und in kleine, junge, zwischen denen zahlreiche Uebergänge existiren. Bei manchen Isopoden (Anilocra) erreichen diese Zellen riesige Dimensionen $(0,35 \mathrm{~mm})$. Die kleineren Zellen sitzen zwischen den grossen, welche letztere wie Zotten in das Drüsenlumen hineinragen (Frenzel, l. c. Taf. IV, Fig. 33). Stets sind sie wie auch bei den Dekapoden an der freien Seite mit einem deutlichen, aber sebr niedrigen Härchensaume 
versehen (Bürstenbesatz). „Der Inhalt der Epithelzellen ist ein verschiedener und zwar je nach ihrem Reifezustande und nach den verschiedenen Isopodenarten. Die reifen Zellen (von Weber als "Leberzellen" bezeichnet) enthalten zunächst überall Fetttropfen, deren Grösse eine variable ist. Sie schwärzen sich schnell in Osmiumsäure, schrumpfen dabei sowie auch bei Behandlung mit Sublimat und lösen sich in Fettlösungsmitteln (Aether, Chloroform). In vielen Fällen sind diese Fetttröpfehen ganz farblos (Anilocra, Id otea, Cyrolana, Cymothoa, Conilera und meist bei Oniseus murarius). Bei Ione und Gyge, Id othea hectica und Sphaerom a erscheinen sie dagegen gefärbt (grünlich- oder bräunlichgelb). Bei den zuletzt genannten Formen enthalten die Drüsenzellen ausser den farbigen Fettkugeln auch noch zahlreiche Krystalle von der g l e ichen F arbe und der Form einer tetragonalen Doppelpyramide. Ihr Verhalten gegen Reagenzien kennzeichnet sie als typische Krystalloide. Sie werden von organischen und anorganischen Säuren schnell gelöst, wobei sie in Essigsäure z. B. quellen, und ähnlich verhalten sie sich gegen Alkalien. In Wasser und absolutem Alkohol, sowie in Aether und Benzin sind sie unlöslich, quellen jedoch in Wasser bei $60^{\circ} \mathrm{C}$. auf. Mit Jod färben sie sich gelbbraun. Ausser diesen Bestandtheilen enthalten die Zellen bei sämmtlichen Is opoden noch staubfeine Granula, die ebenfalls oft gefärbt sind (goldgelb bei Sphaeroma, grünlichgelb bei Id othea hectica, bräunlich bei Cymothoa). Da sich die gleichen Körnchen auch im Secret der Drüse nachweisen lassen, so kann es nicht bezweifelt werden, dass sie von den Zellen wirklich secernirt werden. Einen ungleich höheren Grad der Differenzirung erreicht die Mitteldarmdrüse bei den Dekapoden. Beim Flusskrebs besteht sie jederseits aus zwei gleichartigen Lappen, die sich langgezogen neben dem Oesophagus, Kaumagen und Mitteldarm erstrecken und ihrerseits wieder aus einer überaus grossen Zahl von Blindschläuchen bestehen, die zu secundären Läppchen zusammentreten. Jeder der grossen Drüsenlappen ist zunächst von einer bindegewebigen Membran umhüllt und von den benachbarten Organen abgegrenzt. Doch auch die secundären Läppchen sind innerhalb der gemeinsamen Hülle wieder durch bindegewebige Septa von einander geschieden. Ueber der Tunica propria jedes einzelnen Blindsäckchens findet sich auch hier wieder ein ähnliches Netz von Muskelfasern ausgespannt wie bei den Isopoden. 
Schon Meckel und Lereboullet sowie Frey and Leukart fanden das Epithel der Drüsensehläuche bei den Dekapoden aus zweierlei Zellen zusammengesetzt, welche Meckel als fett- und bilinhaltige Zellen, Lereboullet als Fettzellen und cellules biliaires bezeichnete. Auch Frey und Leukart sahen die ersteren als Fettzellen an, während sie die letzteren nur "Zellen mit wasserklarem Inhalt" nannten. Mit den Fetttröpfchen sollte nach ihnen der Farbstoff der Galle innig verbunden sein. Auch M. W e b e r (l. c.) kommt zu dem Resultat, dass seine "Leberzellen" (die grossen reifen Drüsenzellen) „einen fettartigen Körper bilden, an welchen der thierische Farbstoff gebunden ist", und dass die "Fermentzellen", also die zweite Zellenart, mit einem "wasserhellen Secretbläschen" behaftet sind. Auch bei den Caprelliden fand P. Mayer zwei Arten von Zellen, von denen die einen, fetthaltigen, mit den ${ }_{n}$ Leberzellen" Weber's identisch sind. Doch fand er in den anderen („Fermentzellen“ Weber's) nicht eine wasserklare Blase, sondern einen intensiv gefärbten, nicht flüssigen Secretballen.

Die fetthaltigen Zellen der Mitteldarmdrüse der Dekapoden bilden nach Frenzel grosse langgestreckte Cylinderzellen, welche am freien Ende einen fein gestreiften, schmalen Saum (Bürstenbesatz) tragen. Der grösste Theil des Zellkörpers erscheint von stark lichtbrechenden, kugeligen Gebilden verschiedener Grösse erfüllt. Selten findet sich nur ein einziger grosser Tropfen in ter Zelie, häufiger zwei neben einer grösseren Zahl kleinerer Tröpfchen.

Die meisten Dekapoden jedoch besitzen eine grössere Anzahl fast gleich grosser Kügelchen, die bisweilen sehr klein bleiben. Was ihre Farbe betrifft, so erscheinen sie in den meisten Fällen innerhalb der Zelle farblos, seltener bräunlich oder gelb. Oft sind in einer Zelle alle Kugeln gefärbt, während sich in anderen Zellen derselben Drüse nur farblose finden, oder es kommen in einer und derselben Zelle neben vielen farblosen Tropfen nur wenige, ja oft nur ein einziger gefürbter vor. Stets stimmt die Farbe der Secretkugeln mit der der noch zu erwähnenden Fermentzellen im Tone überein. Wie P. Mayer bereits bei den Caprellen fand und Frenzel bestätigen konnte, färben sich die hellen Kugeln, sobald sie in das Drüsenlumen und in dessen braunen Inhalt gelangen, sofort mit dessen Farbe. Sie sind also im Stande, Farbstoff a ufzunehmen. Dasselbe zeigt sich, wenn man ein Zupfpräparat einige Zeit stehen lässt, denn die freischwimmenden, vorher völlig 
farblosen Tropfen nehmen dann alle eine braune Färbung an. Ihre Fettnatur verräth sich durch ihr Verhalten zu Osmiumsäure, sowie zu Aether und Chloroform, in welchen Flüssigkeiten sie sich ohne Rückstand lösen.

Extrahirt man eine Drüse mit Aether, so erhält man in reichlicher Menge einen intensiv braunen, ölartigen Körper, welcher auf Papier einen deutlichen Fettfleck macht und beim Stehen an der Luft nach einiger Zeit ranzig wird (J. Frenzel). Die Zellen erwiesen sich nachher frei von den erwähnten Tropfen.

Weber gelangte durch makrochemische Untersuchungen des Secretes, indem er Gallenproben anstellte, zu dem Schluss, dass diese fetthaltigen Zellen als echte Leberzellen anzusehen seien. Nach seiner Annahme fungirt die Mitteldarmdrüse als "Hepatopankreas". Auf mikrochemischem Wege konnte Frenzel hierfür keinen Beweis erbringen, denn behandelt man ein Zupfpräparat mit $\mathrm{HNO}_{3}$ (Ğ m el i n'sche Reaction), so nehmen die Zellen keine charakteristische Färbung an.

In etwas geringerer Anzahl als die fetthaltigen Zellen kommen die eigentlichen Fermentzellen in den Drüsenschläuchen vor. Losgelöst erscheinen sie meist fast kugelig, in situ dagegen becher-, ei- oder trichterförmig. Es lässt sich zeigen, dass die Zahl der Fermentzellen im normalen Zustande, wenn das betreffende Thier reichliche Nahrung hat und gut verdaut, bedeutend grösser ist als im Hungerzustande, und man sieht schon daraus, welch wichtige Rolle sie bei der Verdauung spielen. Lässt man einige De ka p o de $n$ absichlich hungern, so zeigt sich dies in unzweideutiger Weise, und schon äusserlich ist es dadurch sichtbar, dass die Drüse meist heller und weniger gefärbt aussieht (so z. B. bei Scyllarus, Palaemon u. s.w.), während die Fettzellen von diesen Verhältnissen ganz unabhängig sind. Auch die Fermentzellen besitzen eine Cuticula mit einem Härchensaum. "Das Secret, welches räumlich den Hauptbestandtheil bildet, stellt einen runden Ballen von $\mathrm{Ei}$ - oder Kugelgestalt dar, welcher in völlig reifem Zustande den grössten Theil der Zelle ausfüllt und nur oben und unten einen schmalen Saum übrig lässt. Dieser Ballen besteht aus einer membranösen Blase, welche bei allen Dekapoden einen körnigen und gefärbten Inhalt führt. Dies ist nicht nur bei den Seekrebsen, sondern auch bei den Süsswasserkrebsen (Astacus fluviat.) der Fall. Meist ist der Inhalt der Blase hell- oder dunkelbraun gefärbt, und 
von seiner Farbe hängt die des Drüsensecretes wie auch die der ganzen Drüse ab. Nur selten (Palaemon serratus, Scyllarus) erscheint der Zellinhalt grün. Im normalen Zustande besteht der Blaseninhalt aus einer feinkörnigen Masse, welche häufig zu einzelnen Klumpen geballt ist, zwischen denen sich schmale, hellere Zwischenräume befinden. Zwischen diesen braunen Granulis vertheilt befinden sich oft andere grössere von starkem Lichtbrechungsvermögen oder selbst grössere Tröpfchen von brauner Farbe. Häufig ist nicht die ganze Blase mit diesen Granulis erfültt, sondern es finden sich nur einzelne Klümpchen oder Bällehen davon vor. Schliesslich findet man auch nicht selten Individuen, wo von diesem gefärbten granulösen Inhalt nichts zu sehen und nur eine farblose oder schwach gefärbte, stark lichtbrechende Flüssigkeit vorhanden ist. Es ist dies besonders bei sich häutenden Thieren der Fall, welche eine Zeit lang nichts fressen. Lässt man einige Exemplare mehrere Tage in filtrirtem Seewasser hungern, so wird die Mitteldarmdrüse mehr oder weniger hellfarbig, und der braune Inhalt der Fermentblasen ist zum grossen Theil oder ganz verschwunden (Scyllarus, Dromia, Carcinus)" (J. Frenzel).

Gegen $0 \mathrm{~s} m \mathrm{i} \mathrm{u} \mathrm{m}$ ä u re verhalten sich die braunen Körnchen ganz indifferent, ebenso gegen verdünnte $\mathrm{HCl}(10 \%)$; in sehr stark verdünnter $\mathrm{HCl}(1 \%)$ quellen die Zellen rasch auf, während sich die Granula zu einer braunen Flüssigkeit lösen. C o n ce n trirte $\mathrm{HNO}_{3}$ löst die Körnchen nicht, entfärbt sie aber nach längerer Zeit, ebenso auch sehr verdünnte Essigsäure $\left(1 \%\right.$ ). Durch $\mathrm{NH}_{3}$ oder $\mathrm{KOH}$ werden die Körncĥen unter Quellung rasch gelöst und entfärbt. $\mathrm{NaCl}-\mathrm{Lösung}(10 \%)$ erhält die Zellen und ihren Inhalt lange unverändert, während verdünnte Lösungen $\left({ }^{3} / 4 \%\right)$ sie rasch zerstört und die braunen Körnchen löst. Durch Alkohol, A ether oder $\mathrm{Chl}$ o r of orm wird der braune Farbstoff extrahirt, ebenso durch Aqua destill. und Glycerin, wobei jedoch die Granula selbst nicht gelöst werden.

Bei vielen Dekapoden (besonders Maja, Carcinus, Callianassa, Squilla, Dromia) finden sich innerhalb der Secretblase häufig lange, farblose Krystallnadeln (1. c. Fig. 20) theils vereinzelt, theils strahlig angeordnet und in ihrer Form durchaus an Tyrosin erinnernd, womit auch ihr mikrochemisches Verhalten stimmt. Unlöslich in Alkohol, Aether und verdünnter Essigsäure, sind sie schwer löslich in Wasser und concentrirter Essigsäure, leichter 
in Kalilauge, wässeriger und alkoholischer $\mathrm{NH}_{3}$-Lösung und in $\mathrm{HNO}_{3}$. Aus der essigsauren und ammoniakalischen Lösung scheiden sie sich beim Verdampfen wieder aus. Es gelang J. Frenzel, auch durch Extraction mehrerer Mitteldarmdrüsen von Maja mit 30\% Alkohol reichliche Mengen von Tyrosin zu gewinnen, was insofern von Interesse ist, als bekanntlich auch im Pankreas der Wirbelthiere, mit welchem, wie wir sehen werden, die Mitteldarmdrüse der Crustaceen hinsichtlich ibrer physiologischen Bedeutung die grösste Aehnlichkeit hat, unter Umständen beträchtliche Mengen von Tyrosin enthält.

In Bezug auf die Bildung des Secretes selbst hätte man es hier mit einem jener seltenen Fälle zu thun, wo die reifen Drüsenzellen (die dann nur noch aus der grossen Fermentblase, dem ganz schmalen Kern und einer Spur Plasma bestehen) sich ablösen und als Ganzes zu Grunde gehen. Noch ehe die Blase in den Darm gelangt, geht dieser Kernrest ganz verloren, und diese bleibt allein noch übrig. "Das Drüsenlumen und die Ausführungsgänge sind mit einer meist braunen Flüssigkeit erfüllt, in welcher die mit den braunen Granulis gefüllten Blasen schwimmen. Die Flüssigkeit und besonders ihre braune Farbe rühren zum Theil ohne Zweifel von diesen Blasen her, indem deren Inhalt schon innerhalb der Drüse gelöst wird. Die meisten derselben gelangen jedoch unversehrt und unverändert in den Magen und theilweise auch in den Enddarm, denn sowohl dort wie hier sind sie unter normalen Verhältnissen immer zu finden. Schon im Magen und noch weiter im Darme verändern sie nun allmählich ihr Aussehen: der braune körnige Inhalt verschwindet naeb und nach, und die Blase selbst collabirt, so dass ihre Membran jetzt deutlich sichtbar wird. Im letzten Theile des Enddarmes sind sie schliesslich ihres Inhaltes gänzlich beraubt und völlig entfärbt. Es scheint sogar noch die Membran aufgelöst zu werden, da häufig im Kothe nichts davon zu sehen ist, während sie im Enddarm noch nachweisbar ist. Wie gezeigt wurde, sind die braunen Granula in dünnen Säuren, Alkalien, Kochsalzlösung und sogar in Wasser leicht löslieh, es ist daher erklärlich, dass sie durch die Flüssigkeit, welche sich im Darmeanal befindet, gelöst und extrahirt werden" (J. Frenzel).

Ist aus irgend einem Grunde die Ernährung gestört und die Verdauung unterbrochen, so werden zunächst noch die gleichen Blasen in den Darm secernirt; sie erfahren aber beim Passiren des Darmtractus eine geringe oder unter Umständen auch gar keine Veränderung und lassen sich sowohl im Enddarm wie im Kothe 
in Menge nachweisen. Bei fortgesetztem Fasten scheinen weniger Fermentzellen frei zu werden und ist der Inhalt der Blasen von vornherein ein farbloser, wie schon erwähnt wurde. Sie finden sich daher auch in demselben Zustande im Darm und im Kothe wieder, während sie normaler Weise im letzteren fehlen. (Maja, Carcinus, Dromia, Portunus.) „Ganz anders liegen die Verhältnisse bei den fetthaltigen Zellen. Wie P. Mayer bei den Caprellid en gefunden bat, wird das Fett aus den Zellen in Tropfenform abgeschieden und nimmt im Drüsenlumen die Färbung der übrigen Flüssigkeit an. Bei den Dekapoden fliessen oft mehrere Fetttropfen zusammen, andere aber scheinen in der Drüsenflüssigkeit gelöst zu werden. Immerhin gelangt ein grosser Theil derselben in den Magen und den Enddarm, wo sie wahrscheinlich gelöst oder sonstwie chemisch verändert werden, so dass sie versehwinden, denn im letzten Stück des Darmes und im Kothe sind nur wenig oder gar keine Fetttropfen wahrzunehmen" (J. Frenzel). Es wird demnach das Secret der Mitteldarmdrüse in erster Linie von dem Inhalt der Fermentblasen geliefert, und weiterhin enthält es noch Fett oder Stoffe, welchevon diesem herrühren. M. Weber legte besonderes Gewicht darauf, dass der Farbstoff der Drüse an die Fettzellen gebunden sei, und dass man dieses Pigment mit den Gallenpigmenten "functionell gleichwerthig erachten" dürfe. Da sich jedoch später herausstellte, dass der Farbstoff gerade den "Fermentzellen" eigenthümlich ist, während der Inhalt der Fettzellen nur unter Umständen pigmentirt erscheint, so würde man noch eher berechtigt sein, jene als Leberzellen $\mathrm{zu}$ bezeichnen.

Nun hat aber bereits Hoppe-Seyler (1. c.) festgestellt, „dass von Gallenbestandtheilen in der Verdauungsdrüse des Krebses nichts zu finden ist." Ebensowenjg gelang ein solcher Nachweis Frenzel beim Flusskrebs und den verschiedenen Seekrebsen. „Zunächst wurden mehrere Drüsen mit Wasser extrahirt, das Extract, nachdem es bis zur Siedetemperatur erhitzt worden, filtrirt und das Filtrat der Pettenkofer'schen Probe unterworfen. Diese ergab nicht die verlangte violette Färbung der Flüssigkeit. Ebenso liess die Gmelin'sche. Probe, an einem auf dieselbe Weise hergestellten Filtrat angewendet, nicht die gewünschten Farbenringe entstehen, sondern nur eine schwach grüne Grenzzone wurde im Reagenzglas sichtbar." Auch eine genauere Methode führte nicht zum Ziele. 
„Nach der Angabe von Gorup-Besanez wurden die Mitteldarmdrüsen von ca. 15 verschiedenen Dekapoden mit absolutem Alkohol ausgezogen, das Extract wurde eingedampft und noch ein Mal mit absolutem Alkohol behandelt und filtrirt. Das wieder eingedampfte Filtrat wurde in Wasser gelöst, filtrirt und mit Bleiacetat und $\mathrm{NH}_{3}$ gefällt. Der ausgewaschene Niederschlag wurde in heissem Alkohol gelöst und die Lösung verdampft, nachdem sie mit $\mathrm{Na}_{2} \mathrm{CO}_{3}$ versetzt war. Wurde der von Neuem in Alkohol gelöste Rückstand nun mit Aether versetzt, so entstand kein harziger Absatz und überhaupt kein Niederschlag, so dass die Pettenk ofer'sche Probe gar nicht erst zur Anwendung kommen konnte. Man muss hieraus schliessen, dass weder Gallensäuren noch die bekannten Cholate sich in den Mitteldarmdrüsen der Dekapoden vorfinden. Ebensowenig gelang der Nachweis von Biliverdin oder Bilirubin, so dass demnach keine Berechtigung vorliegt, die Mitteldarmdrüse der Krebse als "Leber" oder mit M. Weber als "Hepatopankreas" zu bezeichnen ${ }^{1}$ ).

Von organischen Substanzen ist ausser den schon genannten Tyrosin und Leucin nachgewiesen worden, welches J. Frenzel aus dem alkoholischen Extract in mikroskopischen Krystallen gewann. Die Behandlung der Drüsen mit Alkohol., abs. sowie mit Aether ergab ferner ein braungefärbtes Oel (aus den Fettzellen stammend), aus welchen sich noch ein talgartiges Fett abschied. Das Aetherextract lieferte ferner $\mathrm{Ch}$ olesterinkrystalle, welche sich durch die Mol eschott' sche Probe mit $\mathrm{H}_{2} \mathrm{SO}_{4}$ erkennen liessen (J. Frenzel). Fügt man dem Secret unter dem Mikroskop $\mathrm{NH}_{3}$ hinzu, so bilden sich reichliche Mengen von Trippelphosphatkrystallen, was auf einen erheblichen Gehalt an Phosphor und Magnesium hinweist. Durch einfaches Eintrocknen und Auskrystallisirenlassen kann man ferner $\mathrm{NaCl}$ in grosser Menge nachweisen. Zusatz von $\mathrm{H}_{2} \mathrm{SO}_{4}$ liefert Krystalle von $\mathrm{CaSO}_{4}$.

Der erste, welcher der bis dahin als "Leber" bezeichneten Mitteldarmdrüse der Crustaceen (für Astacus fluivat.) die Rolle einer echten Verdauungsdrüse zuerkannte, war Hoppe-Seyler (l. c. 1877). Er fand im Magen (d. h. im Kaumagen) des Flusskrebses "eine reichliche Quantität gelb bis braun gefärbten Magensafteș von

1) Noch jüngst (Anatom. Anzeiger Bd. 24 S. $97 \mathrm{ff} .1903$ ) hat A. Porta wieder die Anwesenheit echter Gallenbestandtheile im Secrete gewisser Drüsen des Verdauungstractes der Insecten behauptet. Eine Nachprüfung dieser Angaben scheint dringend erforderlich. 
schwach saurer Reaction". "Die Flüssigkeit filtrirt gut, ist nicht schleimig, enthält wohl stets Peptone und zeigt sehr energische Fermentwirkung, aber ganz verschieden von Pepsin."

"Fibrinflocken werden in kurzer Zeit in der Flüssigkeit bei gewöhnlicher Temperatur ohne Quellung bis auf geringen bleibenden Rückstand gelöst; bei $40^{\circ} \mathrm{C}$. geschieht dies in wenigen Minuten. Durch Alkohol oder Kochen coagulirtes Fibrin oder Serumalbumin wird langsamer, aber schliesslich in gleicher Weise gelöst; am längsten widersteht coagulirtes Eieralbumin; stets ist die Wirkung bei $40^{\circ}$ bedeutend schneller als bei $15^{\circ}$; aber auch bei der letzteren Temperatur wird $1 \mathrm{~g}$ feuchtes Fibrin von dem Mageninhalt eines Krebses in 24 Stunden bis auf einen geringen bleibenden Rückstand gelöst. Zusatz geringer Spuren von $\mathrm{HCl}$ zur Magenflüssigkeit verlangsamt die Verdaung sofort, und fügt man einige Tropfen einer $0,2 \%$ Salzsäure hinzu, so steht die Verdauung still. Auch in solcher verdünnter $\mathrm{HCl}$ gequollenes, dann in Wasser gut ausgewaschenes Fibrin löst sich viel langsamer als unverändertes Fibrin. Fällt man den filtrirten Magensaft mit Ueberschuss von Alkohol und löst den Niederschlag dann in $\mathrm{H}_{2} \mathrm{O}$, so zeigt diese Lösung wieder entsprechend der Concentration kräftig verdauende Einwirkung auf Fibrin, löst man den Niederschlag statt in Wasser in $0,1 \% \mathrm{HCl}$-haltiger Salzsäure, so erhält man eine nur äusserst langsam oder gar nicht verdauende Flüssigkeit. Das mit Alkohol gefällte Ferment löst sich in Glycerin und kann daraus durch Fällung mit Alkohol und Lösen in Wasser wieder erhalten werden."

Mit Rücksicht auf dieses Verhalten neigt daher H op p e-S e y l e r der Ansicht zu, dass das proteolytische Enzym des Krebsmagensaftes, dessen Herkunft aus der Mitteldarmdrüse er bereits erkannte, nicht sowohl dem Pepsin als vielmehr dem eiweissverdauenden Ferment des Pankreas der Wirbelthiere (Trypsin) nahe steht oder mit ihm identisch ist. "Eine eigentliche Magen- (d. h. Pepsin-) Verdaung, wie sie den Wirbelthieren eigen ist, fehlt den Krebsen ganz, und sie besitzen dafür enorm grosse Drüsen von den Eigenschaften der Bauchspeicheldrüse" (Hoppe l. c.). Demgegenüber vertritt C. W. Krukenberg (1. c.) die Ansicht, dass, wie er es auch für das Secret des Mitteldarmes von Blatta annimmt, das "Astacuslebersecret" neben einem tryptischen auch ein peptisches Enzym 
enthält. Um das erstere zu zerstören, extrahirte Krukenberg die zerkleinerten Mitteldarmdrüsen mit einer $2 \%$ igen Milchsäureoder einer $0,1-02 \%$ igen HCl-Lösung 8 Stunden lang bei $38^{\circ} \mathrm{C}$, während durch einen Zusatz von Salicylsäure faulige Zersetzung ausgeschlossen wurde. Die angedaute Masse wurde ausgepresst, filtrirt und in je zwei Portionen vertheilt, von denen die eine mittels Soda neutralisirt und auf einen Gehalt von $1 \%$ an diesem Salze gebracht wurde; die andere Portion blieb unverändert. Die Flüssigkeit, welche sauer geblieben war, hatte im Laufe von 2 Stunden eine eingelegte Fibrinflocke bis auf einen unbedeutenden Rückstand verdaut, während die Portionen von alkalischer Reaction selbst nach Tagen die Flocken unverändert liessen.

"Die Wirkung in salzsaurer Lösung bleibt nur dann aus, wenn man den wässerigen Drüsenauszug oder das Secret mit HCl versetzt, weil der entstehende Niederschlag viel oder alles Enzym mit niederreisst," worauf $\mathrm{Krukenberg}$ die negativen Resultate von HoppeSeyler zurückführen möchte. Von der Voraussetzung ausgehend, dass das peptische Enzym durch längere Digestion bei $40^{\circ} \mathrm{C}$. mit Sodalösung, das tryptische hingegen durch längere Digestion mit $\mathrm{HCl}$ bei gleicher Temperatur zerstört wird, versuchte $\mathrm{Krukenberg}$ sich möglichst reine Lösungen der beiden von ihm angenommenen Enzyme zu verschaffen. Es zeigte sich das peptische Ferment in salzsaurer $(0,1-0,2 \%)$, weinsaurer $(0,4-2 \%)$, essigsaurer $(0,2-2 \%)$ und milchsaurer $(0,4-2 \%)$, nicht aber in oxalsaurer Lösung $(0,4-2 \%)$ wirksam. Gekochtes Fibrin liess sich weder in milchsaurer noch in salzsaurer Lösung verdauen.

Zu Gunsten seiner Annahme von zwei verschiedenen proteolytischen Enzymen im Secret der Mitteldarmdrüse von Astacus macht Krukenberg weiterhin auch noch die Thatsache geltend, dass verschiedene Crustaceen sich in dieser Beziehung keineswegs ganz gleichartig verhalten. „Bei Eriphia spinifrons und $\mathrm{Squilla} \mathrm{mantis}$ konnte weder durch Ansäueru des Glycerinextractes mit $\mathrm{HCl}$ noch durch Extraction mit 0,2\% HCl-Lösung eine peptische Wirkung auf rohes oder gekochtes Fibrin erzielt werden; in einer Lösung von $2 \%$ Sodagehalt wurde aber vom natürlichen Verdauungssafte, sowie von dem wässerigen und Glycerinauszuge der Mitteldarmdrüse rohes und gekochtes Fibrin sehr bald verdaut." Demnach würde es sich in diesem Falle um ein rein tryptisches Enzym handeln. Im Gegensatze hierzu scheint dieses wieder beim $\mathrm{Hu}$ m mer ganz zurückzutreten. 
„In einer Lösung von $0,2 \% \mathrm{HCl}$ wirkte das Glycerinextract und der im Magen angesammelte Verdauungssaft in wenigen Minuten verdauend auf rohes, nicht aber gekochtes Fibrin, während dieselbe Menge des Glycerinauszuges erst nach 20 Stunden eine gleich grosse Flocke rohen Fibrins in $2 \%$, wicht thymolisirter Sodalösung verdaut hatte. Auch der natürliche Verdauungssaft, der wie das Lebergewebe eine schwach saure Reaction besass, wirkte auf einen Gehalt an 2\% Soda gebracht, im Laufe von 12 Stunden auf rohes Fibrin nicht verdauend ein." Der Mageninhalt zeigte eine kräftige peptische Wirkung auf rohes Fibrin in $0,2 \% \mathrm{HCl}, 2-4 \%$ Essigsäure, $1-4 \%$ Weinsäure und 1-4\% Milchsäure. In Oxalsäurelösungen von gleicher Concentration fehlte jede Wirkung und blieb auch aus, wenn nach 12 stündiger Digestion der oxalsäurehaltigen Verdauungsflüssigkeit bei $38^{\circ} \mathrm{C}$. die Oxalsäure durch Dialyse entzogen und dureh $\mathrm{HCl}$, resp. Soda ersetzt wurde. Bei Zusatz von Borsäure $(0,5-4 \%)$ fehlte ebenfalls die proteolytische Wirkung, doch wurde das Enzym nicht zerstört, indem nach Zusatz von $\mathrm{HCl}$, Milchsäure, Essigsäure oder Weinsäure Verdauung eintrat. Von der Energie des Hummerfermentes sollte folgender Versuch von $\mathrm{Kr}$ uken berg ein gute Vorstellung geben. Einem halben Liter $0,2 \% \mathrm{HCl}$ wurde bei $40^{\circ} \mathrm{C}$. so lange rohes Fibrin zugesetzt, bis in der Gallerte ein eingesteckter Glasstab stehen blieb. Der Glycerinauszug $(10 \mathrm{~g})$ von etwa $1 / 16$ der Mittel/armdrüse wurde dann hinzugefügt. Nach 2 Stunden war alles Fibrin verdaut und in eine Fü̈ssigkeit verwandelt. "Gleiche $10 \mathrm{~g}$ desselben Glycerinextractes, der in so kurzer Zeit so grosse Quantitäten von rohem Fibrin in lösliche Substanzen übergeführt hatte, waren nicht im Stande, binnen 50 Stunden auch nur eine Flocke gekochten Fibrins in $0,2 \% \mathrm{HCl}$ peptisch zu verändern. Krukenberg sehlägt daher vor, dieses durch seine Unwirksamkeit in oxalsäurehaltigen Lösungen und durch seine vollständige Wirkungslosigkeit dem gekochten (coagulirten) Fibrin gegenüber charakteristische peptische Ferment als „Hom aropepsin" zu bezeichnen, und ist der Meinung, dass es in allen den Fällen vorkommt, wo überhaupt bei Arthropoden ein in $0,2 \% \mathrm{HCl}$ rohes Fibrin verdauendes Ferment nachweisbar ist.

Aehnliche Verhältnisse wie beim $\mathrm{Hummer}$, d. h. ausschliesslich peptische Verdaung, fand Krukenberg auch noch bei Nephrops norvegicus, während das Secret der Mitteldarmdrüsen von Maja verrueasa und squinado, Palinurus vulgaris 
und Carcinus maenas sowohl ein tryptisches wie ein peptisches Enzym enthalten soll.

Als Producte der peptischen Verdauung führt Krukenberg Albumosen (Hemialbumose) und Peptone an. Wurde eine genügende Menge rohen Fibrins mittelst "Homaropepsin" verdaut, mit $\mathrm{NaOH}$ neutralisirt und von dem zähen Niederschlag abfiltrirt, so liessen sich durch Dialyse des Filtrates "Peptone" gewinnen; „das Dialysat nahm auf Zusatz von $\mathrm{NaOH}$ und $\mathrm{CuSO}_{4}$ eine röthliche Färbung an und färbte sich beim Erwärmen mit dem Millon'schen Reagens intensiv roth".

Das "tryptische Enzym" aller daraufhin untersuchten Arthropoden bildet nach Krukenberg aus den Eiweissstoffen neben Peptonen in reichlicher Menge den durch Bromwasser sich röthenden Körper (Tryptophan), während dagegen Leucin und Tyrosin angeblich fehlen sollen, was allerdings wohl sehr zu bezweifeln sein dürfte.

In sehr auffallendem Widerspruch mit Krukenberg's Annahmen bezüglich der Verbreitung der beiden Enzyme stehen seine eigenen Angaben über die Reaction der Mitteldarmdrüsen und ihres Secretes bei verschiedenen Krebsen. Bei Astacus, wo die tryptische Verdauung vorwalten oder wenigstens in gleichem Grade wie die peptische entwickelt sein soll, fand schon Sehlemm (1844) saure Reaction, was Lindner (l. c.) und später Hoppe-Seyler bestätigten; beim Hummer mit rein peptischer Verdaung reagirt das Secret "sehwach sauer"; bei Maja squinado mit peptischen und tryptischen Enzym fand Krukenberg die "Leber so gut wie neutral", den Magensaft sowie den Inhalt des Anfangstheiles vom Darm „neutral oder schwach alkalisch". Der Verdauungssaft im Magen von Maja verrucosa reagirte bald neutral, bald sauer. Bei Carcinus maen as war der Verdaungssaft alkalisch, das "Lebergewebe" reagirte alkalisch bis sehr schwach sauer. Krukenberg selbst findet es „vollkommen unverständlich, wie ein Enzym im Dienste der Verdauung wirken kann, wenn in dem Hauptverdauungsraume die Reaction seine Wirkungsfähigkeit verhindert oder wenigstens in hobem Grade beeinträchtigt," und ist sich auch der Seltsamkeit der Annahme bewusst, "dass zugleich in dem Lebersecret von Astacus (und anderen Krebsen) sich neben dem tryptischen Enzym, welches erst in einem nachfolgendem Verdauungsbezirke (eventuell) seine Verwendung finden könnte, ein peptisches vorhanden ist, das jenes nach nur einigermaassen lange währender 
Einwirkung zu zerstören vermag". Bei Astacus fluviatilis ist die functionelle Bedeutung des tryptischen Enzyms vollkommen unklar; es wird im Magen, dessen Inhalt nur von saurer Beschaffenheit gefunden werden konnte, bereits gänzlich zerstört, und der alkalische Darminhalt, an welchem es seine Wirkung äussern könnte, enthält absolut nichts mehr davon. Bei der Periplaneta orientalis hingegen dürfte dem Pepsin eine untergeordnete Bedentung zukommen, weil bei ihr die Eiweissverdauung besonders im sogenannten Chylusdarme, also bei neutraler oder alkalischer Reaction, ablaufen wird. Ganz bedeutungslos wird das peptische Enzym bei Hydrophilus piceus sein, dessen Mitteldarmsecret von diesem auch nur geringe Mengen enthält" (Krukenberg l. c. Bd. II Heft I S. 37). Demungeachtet bezeichnet es Krukenberg "als das wichtigste Ergebniss" seiner Untersuchungen an Crustaceen und Insecten, „dass eines der beiden Enzyme für den Verdaungsact fast vollständig nutzlos ist, "welcher merkwürdige Thatbestand nothwendig zu einer Erklärung auffordere.

Bei aller Unvollkommenheit des bis jetzt vorliegenden Versuchsmateriales scheint mir aber doch so viel aus der Vergleichung der zahlreichen Einzelthatsachen hervorzugehen, dass ein wirklich zwingender Beweis für die Annahme von $z$ wei verschiedenen Enzymen zur Zeit nicht geliefert ist. Bei Krakenberg selbst findet man in dieser Beziehung eine merkwürdige Unsicherheit. Beim Flusskrebs hatte er gefunden, dass ein Extract der Mitteldarmdrüse rohes, aber nicht gekochtes Fibrin in $0,2 \%$ iger HCl-Lösung, gekochtes dagegen nur in 2\%iger Essigsäure zu lösen vermag, welche letztere Eigenschaft den essigsauren Auszügen der Hummer- und Nephropsleber ganz fehlen soll. Ob es sich hier um ein specifisch verschiedenes zweites peptisches Enzym oder um eine besondere Eigenschaft des beim Flusskrebs vorwaltenden tryptischen Fermentes handelt, lässt K rukenberg unentschieden. Man wird zugeben, dass die Annahme von sogar drei verschiedenen proteolytischen Enzymen in einem und demselben Verdauungssecrete in höchstem Grade unwahrscheinlich ist. Bezieht man aber die Fähigkeit, auch in saurer Lösung zu verdauen, auf ein tryptisches Enzym, so steht, wie es scheint, kein Hinderniss im Wege, überhaupt nur ein Ferment anzunehmen, welches die Eigenschaft besitzt, sowohl in neutraler wie in saurer und alkaliseher Lösung Eiweisskörper zu verdauen. In der That bietet ja schon das Trypsin der Wirbelthiere ein hierhergehöriges Beispiel, da es ja erwiesenermaassen im Stande 
ist, auch in schwach saurer Lösung zu verdauen. Die einzige von Krukenberg gegen eine derartige Annahme geltend gemachte Thatsache, dass es nämlich gelingt, das tryptische Enzym in saurer, das peptische dagegen durch Digestion in $2 \%$ iger Sodalösung bei $38-40^{\circ}$ C. zu zerstören, bedarf sicher noch weiterer Prüfung.

In ganz analoger Weise hat sich auch $O$. v. Fürth in seinem verdienstvollen Buche über die vergleichende chemische Physiologie der niederen Thiere bezüglich der K r u k e n b e r g' 'schen Anschauungen ausgesprochen: „Bei nüchterner Betrachtung dieser und ähnlicher Angaben und Reflexionen kann man sich wohl des Eindruckes nicht erwehren, dass eine an sich einfache Sache durch die bestehende Neigung, die objective Beschreibung des Sachverhaltes durch Schlagworte zu ersetzen und überdies um jeden Preis eine Analogisirung mit den Verhältnissen bei höheren Thieren durchzuführen, unnöthig complizirt worden ist. Man muss sich doch darüber klar sein, dass die Begriffe „Pepsin" und "Trypsin“ in der Physiologie der höheren Thiere formulirt worden sind, um für das gänzlich differente Verhalten der fermentführenden Secrete anatomisch gesonderter Drüsenarten einen kurzen sprachlichen Ausdruck zu besitzen. Es entspricht aber sicherlich nicht einer naiven und natürlichen Auffassung, wenn aus der einfachen Beobachtung, dass das Verdaunngssecret eines niederen Thieres seine Wirksamkeit sowohl bei schwach saurer als auch bei schwach alkalischer Reaction zu entfalten vermag, eine Lehre von der Coexistenz zweier sich gegenseitig vernichtender Fermente herausconstruirt wird." (O. v. Fürth l. c. S. 225 f.)

Meine eigenen Untersuchungen haben mir gezeigt, dass sich das Secret der Mitteldarmdrüse vom Flusskrebs, wie man es leicht in grösserer Menge auch am hungernden Thier dnrch Einführen einer Glascanüle in den Mund und Aussaugen gewinnen kann, sowohl in Bezug auf seine Eigenschaften wie die verdauende Wirkung, ganz ähnlich verhält wie der Verdauungssaft des Mehlwurms. Hier wie dort handelt es sich um eine sehr eiweissreiche gelbbräunliche Flüssigkeit, die sich beim Ansäuern (Essig- oder Salzsäure) unter Abscheidung eines feinflockigen Niederschlages trübt, der, abfiltrirt und gewaschen, alle Reactionen eines Globulinkörpers gibt. Das saure Filtrat hat niemals auch nur die Spur verdauender Wirkung gezeigt, gleichgültig welcher Art die zugesetzte Säure war.

In Bezug auf die Reaction des "Magensaftes" muss ich Stamati durchaus widersprechen, indem ich in Uebereinstimmung 
mit Schlemm, Lindner, Hoppe-Seyler und Krukenberg stets fand, dass blauer Lackmusfarbstoff g eröthet wird, also im gewöhnlichen Sinne saure Reaction besteht. Stamati hat beim lebenden Thier eine Magenfistel angelegt, indem er gerade über dem Cardiatheil des Magens den Rückenpanzer eröffnete. "Die Muskulatur wurde aus einander gedrängt, eine kleine Incision gemacht, sodann eine an ihrem Ende erweiterte und mit einem verbreiterten Rande versehene Canüle, mit dem engeren Theil voraus, in den Mund des Thieres eingeführt und durch den Oesophagus hindurch in den Magen geschoben, derart, dass sie in der Incision zum Vorschein kam. Nun wurde die Canüle derart gestellt, dass der verbreiterte Rand sich gegen die Innenwand des Magens stützte und das Rohr nach aussen ragte. Durch einen von aussen über die Canüle geschobenen Kautschukring, der sich gegen den Panzer stemmte, wurde dieselbe in ihrer Lage fixirt und schliesslich der Rand der Wunde mit Collodium verschlossen. Die Thiere überstehen den Eingriff anscheinend ohne wesentliche Schädigung ihrer allgemeinen Condition und konnten Wochen lang beobachtet werden. Durch Umdrehen der Thiere, derart, dass die Mündung der Canüle nach unten zu liegen kam, gelang es, ohne Weiteres jeder Zeit den ,Magensaft' zu gewinnen (cit. nach v. Fürth). Wenn Stamati denselben unter diesen Umständen meist deutlich alkalisch fand, so möchte dies doch wobl auf den operativen Eingriff zu beziehen sein; denn der einfach ausgeheberte Saft, der sich mit grösster Leichtigkeit jeder Zeit und ohne alle Vorbereitung des Thieres gewinnen lässt, röthet Lackmus ausnahmslos. Dass es sich auch hier wie beim Mehlwurm nicht um eine freie Säure handelt, geht ganz überzeugend aus dem sonstigen Verhalten des Saftes hervor. Kongoroth und Günzburg's Reagens erwiesen sich als indifferent, dagegen ist das Verhalten gegen Tinct. coccionellae und rothes Lackmoid sehr charakteristisch. Die erstere wird durch den Saft blauroth gefärbt, während rothes Lackmoidpapier gebläut wird.

Der Krebsmagensaft verhält sich also gegen die beiden letztgenannten Farbstoffe alkalisch, gegen Lackmus aber sauer. Wie beim Mehlwurm erscheint es daher am wahrscheinlichsten, dass ein saures Salz die Röthung des blauen Farbstoffes bedingt (vielleicht Mononatriumphosphat), während zugleich freies Alkali im Secrete vorhanden ist (vgl. Biedermann, P flüger's Arch. Bd. 72 S. 145). 
Wie hinsichtlich der Reaction, so besteht auch bezüglich der enzymatischen Verdauungswirkung des Krebssaftes die grösste Uebereinstimmung mit dem Mitteldarmsecret vom Mehlwurm. Aus schwer ersichtlicben Gründen bat es $\mathrm{Krukenberg}$ bei seinen vergleichend physiologischen Untersuchungen über Verdauung fast immer vorgezogen, künstlich bereitete Extracte der betreffenden Drüsen oder Schleimhäute zu prüfen, während das unter natürlichen Umständen wirksame Secret entweder gar nicht oder vergleichsweise nur wenig Berucksichtigung fand. Ich kann es nur diesem Umstande zuschreiben, dass er zum Theil auf ganz falsche Wege geleitet wurde, die ihn oft weit vom eigentlichen Ziele abführten. Es mag gleich vorausgeschickt sein, dass ich trotz vieler Bemühung nicht in der Lage bin, auch nur einen einzigen der von Krukenberg bezüglich der proteolytischen Wirksamkeit der Mitteldarmdrüse von A stacus aufgesteliten Sätze $\mathbf{z u}$ bestätigen. Alle Extracte, welche möglichst nach Vorschrift Krukenberg's mit Säuren $(0,1-0,2 \% \mathrm{HCl}, 2 \%$ Milchsäure, 0,2-2\% Essigsäure) oder Alkalien aus Krebslebern bereitet wurden, zeigten weder auf rohes noch gekochtes Fibrin die geringste Wirkung, wenn man natürlich von der Säurewirkung selbst absieht. leh habe Tage lang (2-3 Tage) bei $38^{\circ} \mathrm{C}$. digerirt, schliesslich erfolgte eine theilweise Lösung der stark gequollenen Fibrinflocken, die aber in Controllproben mit Säure allein ganz ebenso eintrat. Ich fand aber auch einfache Wasserextracte aus frischen Krebslebern nur wenig wirksam, jedenfalls immer unvergleichlich geringer als das aus dem Magen geheberte Secret. Es ist übrigens leicht ersichtlich, dass, mit Rücksicht auf die neueren Erfahrungen über Autodigestion, Drüsenextracte, welche nach Krukenberg's Methode durch vielstündige Digestion der zerkleinerten Organe mit Wasser oder verdünnter Säure und Alkalilösungen bei $38^{\circ} \mathrm{C}$. gewonnen wurden, kaum etwas Sicheres über die im Secrete selbst wirksamen Enzyme auszusagen vermögen. Wenn es nun ausserdem so leicht und einfach ist, grosse Mengen von reinem Secret (Magensaft) zu erhalten wie bei Krebsen, so lassen sich die Bemühungen Krukenberg's, die Leber selbst zu extrahiren, wohl nur aus der vorgefassten Meinung erklären, dass z w e i verschiedene proteolytische Enzyme in der Drüse gebildet werden.

$\mathrm{Zu}$ einer definitiven Widerlegung dieser von $\mathrm{Krukenberg}$ aufgestellten „Doppelenzymlehre" würde es nun freilich erforderlich sein, auch seine so bestimmt lautenden Angaben über die Verdauung 
anderer Crustaceen abermals zu prüfen und namentlich den H u m mer zu untersuchen, der, wie schon erwähnt, nur ein "peptisch" wirkendes Enzym in seinem Verdauungssafte besitzen soll. Es ist mir leider bis jetzt nicht möglich gewesen, meine Untersuchungen in dieser Richtung weiter auszudehnen. Doch kann ich schon auf Grund der wenigen Versuche, welche ich beim $\mathrm{Hummer}$ anstellte, mit Sicherheit behaupten, dass sich hier die Angaben Krukenberg's ebensowenig bewähren wie beim Flusskrebs. Sehr verdächtig erscheint schon die Bemerkung, dass beim Hummer , in ein er Lösung von $0,2 \% \mathrm{HCl}$. . . der im Magen eingesammelte Verdauungssaft in wenigen Minuten verdauend auf rohes, nicht aber auf gekochtes Fibrin einwirkte", während beim Flusskrebs „die Wirkung in salzsaurer Lösung ausbleibt, wenn man den wässerigen Drüsenauszug oder das Secret mit $\mathrm{HCl}$ versetzt, weil der entstandene Niederschlag viel oder alles Enzym mit niederreisst". Muss man es nicht für äusserst unwahrscheinlich halten, dass bei zwei so nahe verwandten Thieren das Secret der Leberdrüse so verschieden sein sollte, dass nur in dem einen Falle bei HCl-Zusatz ein das wirksame Enzym niederreissendes Sediment entsteht, in dem anderen aber nicht. Warum brachte andererseits Krukenberg den ,natürlichen Verdauungssaft (des Hummers), der wie das Lebergewebe eine schwach saure Reaction (auf Lackmus) besass," erst auf einen Gehalt von $2 \%(!)$ Soda, worauf im Laufe von 12 Stunden jede verdauende Wirkung auf rohes Fibrin ausblieb? Wie beim Flusskrebs, so kann man sich auch ebenso leicht beim Hummer relativ grosse Mengen (mehrere Cubikcentimeter) Magensaft durch Aushebern mittelst einer in den Mund eingeführten Pipette verschaffen. Der Saft ist wie bei Astacus braungelb gefärbt, enthält reichlich Eiweisskörper, die durch geringen Säurezusatz ausgefällt werden, röthet intensiv blaues Lackmuspapier und zeigt, mit einem Worte, die grösste Uebereinstimmung mit dem Lebersekrete unseres Süsswasserkrebses. Mit Chloroformwasser verdünnt und bei etwa $38^{\circ} \mathrm{C}$. mit rohem Fibrin zusammengebracht, zeigt sich sehr bald (schon nach 2-3 Stunden) bröckliger Zerfall des letzteren, der mit fast völliger Lösung endet. Gekochtes (coagulirtes) Fibrin wird unter allen Umständen sehr viel schwerer angegriffen, schliesslich aber zerfällt es auch und wird gelöst. Ganz dasselbe gilt ebenso bezüglich des Magensaftes von Astacus. Auf Essigsäurezusatz entstand auch nach zweitägiger 
Verdauung von rohem Fibrin mit $\mathrm{Hummersaft}$ noch eine reichliche Fällung eines globulinartigen Eiweisskörpers. Desgleichen gab das Filtrat beim Kochen eine starke flockige Trübung, von der wieder abfiltrirt wurde. Die völlig klare Flüssigkeit färbte sich bei Zusatz von Kalilauge und einer Spur $\mathrm{CuSO}_{4}$ schön rosenroth (Albumosen) und lieferte nach dem Neutralisiren beim Eindampfen wohlentwickelte Tyrosindrusen und Le u cinkugeln.

Ein mit $0,2 \% \mathrm{HCl}$ angefertigtes Extract der Mitteldarmdrüse vom Hummererwies sich selbst bei tagelanger Einwirkung rohem Fibringegenüber gänzlich wirkungslos, und ebensowenig vermochte ich mit einem Glycerinextract dẹ Drüse eine merkliche verdauende Wirkung zu erzielen, selbst wenn grosse Mengen davon zu einer $0,2 \%$ igen $\mathrm{HCl}$ - oder $2 \%$ igen Essigsäurelösung hinzugefügt wurden. Die Fibrinflocken quollen, aber lösten sich auch nach Tagen nicht auf. Es ist sehwer verständlich, wie Krukenberg bei dem in der Einleitung beschriebenen analogen Versuch mit in Säure gequollenem Fibrin zu einem so ganz entgegengesetzten Resultate kommen konnte.

Auf alle Fälle muss ich die Existenz der von Krukenberg als "Homaropepsin" bezeichneten Pepsinmodification durchaus bestreiten, wie sich auch nach den Untersuchungen von Biedermann und Moritz das "Helicopepsin" als nicht vorhanden erwiesen hat.

Die alte Auffassung von Hoppe-Seyler, dass im Lebersecret von Astacus, welches sich im Magen angehäuft findet, ein in seiner Wirkung dem Trypsin im Wesentlichen entsprechendes proteolytisches Enzym findet, muss entschieden aufrecht erhalteu werden. Nichts ist leichter, als sich von dieser Thatsache zu überzeugen. Man hebere einem hungernden Krebs den im Magen entbaltenen Saft aus (wobei sich bisweilen mehr als 1 ccm ergibt), verdünne mit etwa $50 \mathrm{cem}$ Chloroformwasser und digerire eine entsprechende Quantität rohen Fibrins in einem verschlossenen Fläschchen bei $30-40^{\circ} \mathrm{C}$, , so beginnt der ohne jede Quellung erfolgende bröcklige Zerfall der Flocken bereits nach 2-3 Stunden. Nach 12 Stunden ist in der Regel alles Fibrin bis auf geringe Reste gelöst. Die klare, schwachgelb gefärbte Verdauungsflüssigkeit gibt bei Zusatz verdünnter Essigsäure einen ziemlich reichlichen feinflockigen Niederschlag eines globulinartigen Eiweisskörpers. Das Filtrat trübt sich beim Kochen neuerdings, worauf abermals filtrirt 
wird. Die klare Flüssigkeit gibt mit $\mathrm{KOH}$ und $\mathrm{CuSO}_{4}$ sehr dentliche Rothfärbung (Albumosen). Auch nach dem Aussalzen mit Ammoniumsulfat fällt die Biuretprobe positiv aus (Peptone), indem nach Zusatz von viel NaOH-Lauge und recht wenig $\mathrm{CuSO}_{4}$ eine schön rosenrothe Färbung eintritt.

Nach dreitägigem Digeriren einer anderen Probe (bei $38^{\circ} \mathrm{C}$.) trat auf Zusatz von Essigsäure keine merkliche Trübung mehr ein, und auch beim Kochen war die Eiweissfällung sehr viel geringer als nach kurzer Verdauungszeit. Eine Probe des klaren Filtrats lieferte, mit Bromwasser versetzt, eine sehr deutliche Trypt ophanReaction. Beim Eindampfen der neutralisirten eiweissfreien Flüssigkeit schieden sich aus dem braunen Syrup so massenhaft Leucinkugeln und Tyrosindrusen aus, dass es schwer $\mathrm{zu}$ begreifen ist, wie Krukenberg zu der Meinung kommen konnte, die genannten beiden Aminosäuren würden durch das "tryptische" Enzym aller Arthropoden überhaupt nicht gebildet. Extrahirt man den Syrup mit kochendem Alkohol und lässt langsam verdunsten, so erhält man noch schöner ausgebildete Leu cin kugeln und Drusen in Masse ohne Tyrosin. Wird dagegen der Rückstand mit heissem Wasser aufgenommen und zum langsamen Verdunsten hingestellt, so fällt, umgekehrt, massenhaft Ty rosin in schön entwickelten Drusen aus, während Leucin so gut wie ganz fehlt. Trotz der überaus charakteristischen mikroskopischen Bilder dieser beiden Aminosäuren habe ich mich doch auch noch durch Anstellung der üblichen Reactionen (Scherer's Probe, Millon's Reaction, Reaction von Piria, vergl. Hoppe-Seyler, Chem. Analyse, VI. Aufl. 1893 S. 135 und 188) von der Qualität der betreffenden Substanzen überzeugt, so dass an ihrem regelmässigen Vorhandensein nicht der geringste Zweifel bestehen kann. Bei einem eben solchen Verdauungsversuch mit $\mathrm{Hu}$ m m er saft entstanden beim lang. samen Verdampfen des heiss bereiteten alkoholischen Auszuges neben Leucin und Tyrosin auch noch grosse wasserhelle Krystalle in grosser Zahl. Ich vermochte jedoch ihre Natur nicht näher festzustellen.

Was nun die Wirkung des Krebs-Magensaftes auf die N-freien Nährstoffe anlangt, so hat schon Hoppe-Seyler Sacharificirung und Fettspaltung beobachten können. Die Verzuckerung einer verdünnten Stärkelösung geht äusserst energiseh vor sich, es lässt sich nach Zusatz weniger Tropfen des aus- 
geheberten frischen Saftes schon in allerkürzester Zeit (0,5-1 Min.) das Vorhandensein von Erythrodextrin und Zucker nachweisen, so dass sich dieser Verdauungssaft zur Demonstration jenes hydrolytischen Spaltungsvorganges ganz besonders gut eignet. Demgegenüber erscheint die Behauptung Krukenberg's, dessen. Vorsicht sonst nicht so gross zu sein pflegt, anffallend, man könne über die diastatische Wirkung des Saftes nichts aussagen, ehe man nicht den stets vorhandenen Zucker aus dem Magensaft entfernt habe. Nach meiner Erfahrung finden sich in dem vom Eiweiss befreiten Saft hungernder Thiere höcbstens Spuren von Zucker. Auch Fett (Milch) wird vom Mitteldarmsecret des Krebses ähnlich wie von dem des Mehlwurmes energisch gespalten. Füge ich noch hinzu, dass nach den Untersuchungen von Biedermann und Moritz das in Rede stehende Secret auch noch eine "Cytase" (Cellulose spaltendes Enzym) enthält, so zeigt sich, dass wir es auch hier mit einem äusserst wirksamen Verdauungssaft zu thun haben, der sich am ehesten dem Pankreassecret der Wirbelthiere vergleichen lässt.

\section{Die resorptive Function der Mitteldarmdrüse.}

Schon vor langer Zeit finden wir die Vermuthung ausgesprochen, dass die "Leber" des Krebses der Resorption der Verdauungsprojecte diene. So citirt bereits Rösel v. Rosenhof (1755) im III. Theile seiner Insectenbelustigungen (S.326): „dass B ell o niu s beym Gesner sage, der Magen des Krebses werde von einer Materie umgeben, so er Matis nennet, welche Viele fälschlich für dessen Koth, er aber für die Leber hielte; und Will is schreibet: an dem Magen seyen zu beeden Seiten zwey drüsigte Körper angewachsen, die voller Gefäse und verwickelter Gänge seyen, auch gleichsam die dünnen Gedärme vorstellen, welche sich hernach mit zwey immer spitziger zugehenden Lappen zu unterst bis in den Leib erstrecken. In diese Körper gehen aus dem Magen einige Oeffnungen, so dass, wenn man in selbigen hineinbläset, die Lufft in dieselben dringet und sie auflauffen machet. Diese Theile werden in den rindichten, wie in den hartschaligten Fischen insgemein für die Leber gehalten, und sie scheynen auch in der That statt der Leber und des Gekrösses dazu seyn, den zärtern Theil des in dem Magen zubereiteten Daungssaffes aufzunehmen, mehr zu reinigen und so denn dem Lebenssafft beyzumischen." 
Die Gründe, welche wenigstens für den Flusskrebs sehr entschieden dagegen sprechen, dass die Resorption der Verdauungsproducte innerhalb des Magen-Darmtractes selbst stattfindet, wurden theilweise schon erwähnt. Sie liegen hauptsächlich in dem B a u des. selben und vor Allem in der dicken inneren Chitinbekleidung. Dazu kommt noch die Kürze des Mitteldarmes der Dekapoden, so dass sich hier in noch viel höherem Grade als bei den Schnecken die Vermuthung aufdrängt, dass die grosse Mitteldarmdrüse auch in diesem Falle das wesentlichste Resorptionsorgan sei, obschon Johannes Frenzel mit aller Bestimmtheit erklärte, dass die zu resorbirenden Stoffe in die Anhänge des Darmrohres, „die grosse Drüse (Leber) und in die dorsalen Schläuche nicht eintreten". Tursin i (Un primo passo nelle ricerche dell' assorbimento intestinale degli Arthropodi; Rend. Accad. Sc. fis. Napoli t. 16 p. 97. 1877) hatte schon früher die Resorption in den Kaumagen verlegt, gewiss den unwahrscheinlichsten Ort für diesen Vorgang. Er hatte Kohlenpulver, gefärbtes Oel und dergleichen in den Magen von Krebsen injicirt und fand stets nach kürzerer oder längerer Zeit gefärbte Partikelchen im Innern der hohlen Chitinhaare. Er nahm daher an, diese Anhangsgebilde seien ganz analog wie die Darmzotten höherer Thiere dazu bestimmt, die Absorption von Verdauungsproducten zu bewerkstelligen. Auch in der Bearbeitung der Crustaceen vou A. Gerstaecker und A. E. Ortmann in Bronn's Classen und Ordnungen des Thierreiches (1901, V, Abth. 2) wird noch der Kaumagen als der für die Resorption wesentlichste Theil des Verdaungstractes bezeichnet, und zwar hauptsächlich aus dem Grunde, weil der Mitteldarm zu klein sei.

Einen wesentlichen Fortschritt verdanken wir den Arbeiten zweier Forscher aus neuerer Zeit: St. Hilaire und Cuénot.

$\mathrm{Cu}$ énot fütterte verschiedene Crustaceen (Astacus, Palaemon, Carcinus, Portunus) mit Fleisch, das mit Fuchsin gefärbt worden war, oder aber injicirte er vom Munde aus zähflüssige Indigokarmin oder Methylgrün enthaltende Nährlösungen. Wurde der in voller Verdauung begriffene Krebs einige Tage später untersucht, so konnte festgestellt werden, dass neben der Strömung, welche das Lebersecret in den Magen leitet, auch noch eine solche existirt, welche die löslichen Verdauungsproducte in die Leber hineinführt. „On constate facilement, que tous les coecums hepatiques sont remplis d'un liquide coloré par les substance ajoutée à la nourriture, mais 
qui ne renferme absolument aucune particule solide." Die Leberschläuche sind von einem Netze von Muskelfasern umsponnen, durch deren Contractionen die Strömungen erzeugt werden dürften. Während das Lebergewebe reichlich Farbstoff aufgenommen batte, war bemerkenswerther Weise der Darm in seiner ganzen Ausdehnung, also auch der Mitteldarm, ganz ungefärbt geblieben. Die Resorption war auf die allerdings colossale Oberfläche der Leberschläuche beschränkt geblieben.

$\mathrm{Zu}$ ähnlichen Ergebnissen war bereits früher St. Hilaire gelangt, indem er bei Flusskrebsen mit Hülfe einer in den $A \mathrm{nus}$ eingeführten und mit einer Pravaz'schen Spritze verbundenen Canüle Farbstofflösungen in den Darm injicirte. Methylenblau wurde in beträchtlicher Menge in die Leber aufgenommen und darin festgehalten, während Vesuvin gleichfalls aufgenommen wurde, sich jedoch dann im Körper weiter verbreitete. Diese Versuche St. Hilaires können aber kaum etwas für die Annahme einer normalen resorptiven Function der Krebsleber beweisen; denn injicirt man Farbstofflösungen per anum bei blossgelegtem Darm am geöffneten Thier, so sieht man, dass es auf diesem. Wege verhältnissmässig leicht gelingt, die Leberschläuche mechanisch zu injiciren. Es ist daher zur Erzielung einwandfreier Resultate durchaus nöthig, die Fütterung per os zu wählen, wie es auch $\mathrm{Cu}$ énot gethan hat. Gute Resultate erzielte ich auch durch „Fütterung" mit Ferrum oxydatum saccharatum. Mittels eines gebogenen Glasrohres brachte ich eine starke Lösung in den Kaumagen, worauf die Thiere in's Wasser gesetzt wurden. Nach 4-5 Tagen, während welcher Zeit die „Fütterung" öfters wiederholt wurde, wurden die Thiere getödtet und die Leber, Pylorus, Mittel- und Enddarm in Sublimatalkohol gehärtet. An Schnitten, mit welchen dann die Berlinerblau-Reaction angestellt wurde, und die mit Carmin nachgefärbt waren, fanden sich in den "Fettzellen" der Mitteldarmdrüse reichliche blaue Vacuolen, im Pylorus, Coecum, Mittel- und Enddarm jedoch nichts.

Da auf Grund der Versuche Cuénots die Aufnahme gelöster Substanzen seitens der Krebsleber ausser allem Zweifel stand, so habe ich mein Hauptaugenmerk auf die Frage gerichtet, ob anch feste Partikel, wie es für die Schneckenleber von Biedermann und Moritz als sichergestellt gelten darf, in die Mitteldarmdrüse eindringen können. Zu dem Zwecke brachte ich den Krebsen zunächst in Wasser aufgeschwemmtes Carminpulver in den Magen, 
woraufsich dasselbein reichlicher Menge in den Leberschläuchen fand. (Fig. 1 u. 2, Taf. VII.) Kaumagen, Pylorustheil und die Ausführungsgänge der Drüse, alles war gleichmässig mit Carminkörnchen erfüllt, so dassein Zweifel über den Weg, den der Farbstoff genommen hat, nicht wohl möglich ist. In die Drüsenzellen selbst drangen die Körnchen niemals ein, was ja mit Rücksicht auf anderweite Erfahrungen nicht $\mathrm{zu}$ verwundern ist. Die nächstliegende Vermuthung, dass die Farbkörnchen mechanisch in die Drüsenausführungsgänge hineingepresst wurden, erscheint aus dem Grunde ausgeschlossen, weil die zwischen Cardia- und Pylorustheil des Magens befindliche Falte diesen von jenem beim Einblasen von Flüssigkeit fast vollständig abschliesst. Eher wird man den Cardiatheil zersprengen, als es gelingt, die Ausführungsgänge der Drüse vom Munde aus zu injiciren. Im günstigsten Falle gelangen winzige Mengen in den Pylorustheil, nie jedoch in der zum "Füttern" nothwendigen Zeit und bei dem angewandten geringen Drucke. Um gute Resultate zu erzielen, muss man die Thiere etwa fünf Tage nach der "Fütterung" leben lassen, während welcher Zeit man gut thut, die "Fütterungen“ $\mathrm{zu}$ wiederholen. Interessant und wieder ganz entsprechend den Befunden an Schnecken ist die Beschaffenheit des Kothes solcher Krebse. Wie dort, lassen sich daran zwei Portionen unterscheiden, dickere wurstförmige Massen von etwa 1,5 mm Durchmesser (dem Darmealiber entsprechend) und feinere fadenförmige Partien von $0,2-0,35 \mathrm{~mm}$ Durchmesser, die offenbar den unverdaulichen aus der Mitteldarmdrüse kommenden Massen entsprechen. Beides besteht in unserem Falle aus fest zusammengepressten Carminkörnchen. "Füttert" man Krebse mit einem ziemlich dickflüssigen Brei von mit Wasser angerührten Mehl- und Lackmuspulver, indem man während 3-5 Tagen täglich eine entsprechende Portion mittelst eines Glasröhrchens durch den Mund in den Magen injicirt, so findet man nachher die Leber schon bei makroskopischer Untersuchung sehr deutlich geröthet und erkennt bei Lupenvergrösserung, dass fast jeder einzelne Schlauch mit einer rothen Flüssigkeit gefüllt ist. Nur äusserst spärlich finden sich dagegen im Lumen der Drüsenschläuche kleinste Stärkekörnchen, die man durch Zusatz von Jod-Jodkaliumlösung leicht sichtbar machen kann. In den meisten Schläuchen konnte ich feste Stärke überhaupt nicht nachweisen. Es besteht also in dieser Beziehung ein bemerkenswerther Gegensatz zur Schneckenleber, in die selbst grosse 
Stärkekörner massenhaft eindringen. Offenbar gestatten beim Krebs die anatomischen Verhältnisse nur den Eintritt feinster körperlicher Elemente. Dem eben erwähnten Versuch kommt übrigens noch insofern eine gewisse Bedeutung $\mathrm{zu}$, als er einwandfrei beweist, dass schon das normale Secret innerhalb der Drüsenschläuchegegen blauen Lackmusfarbstoff sauer reagirt.

Die Resultate der Carminfütterung liessen erwarten, dass es sich mit einer Fettemulsion ganz ähnlich verhalten würde, so dass die Leber auch für Fett die wesentlichste Resorptionsstätte bildete. Indessen hat sich wider Erwarten herausgestellt, dass gerade in Bezug auf diesen Punkt die Verhältnisse nicht so einfach liegen, als es von vornherein den Anschein hatte. Füttert man, wie dies schon $\mathrm{Cu}$ én ot that, Krebse (Astacus, Carcinus, Cancer, Portunus, Eupagurus, Palaemon) mit fettem Fleisch oder mit einem ölhaltigen Teige, so findet man, wenn man die Thiere nach drei Tagen öffnet, Magen und Darm von einer fetthaltigen Emulsion erfüllt. Wird nun der Verdauungstract nach Behandlung mit Flem ming'scher Lösung. untersucht, so vermisst man jede Spur von Fett in den mit einer undurchdringlichen Cuticula versehenen Chitinzellen des Magens und Enddarmes. Dagegen erweisen sich (nach Färbung mit Osmiumsäure) sämmtliche Zellen des Mitteldarmes von Fetttröpfchen durchsetzt; die letzteren finden sich im Protoplasma vertheilt, lassen jedoch den innersten Theil der Zelle frei. Untersucht man den Darm hungernder Thiere, so findet sich in keiner Epithelzelle auch nur eine Spur von Fett. Durch Beobachtungen von Hardy und Dougall an lebenden Daphnien wurde festgestellt, dass die Fettresorption bei diesen Thieren vorwiegend im vorderen Drittel des Mitteldarmes erfolgt. Die Ausdehnung des Mitteldarmes, die für die Fettresorption zur Verfügung steht, ist je nach der Gattung ausserordentlich verschieden. So entfällt bei Astacus und Galathe auf den Mitteldarm nur etwa ein Zwanzigstel der gesammten Darmlänge, während bei den Paguriden der Mitteldarm etwa zwei Drittel der ganzen Ausdehnung des Verdauungstractes umfasst und überdies durch eine reichliche Ausbildung von Blindschläuchen eine weitere Vergrösserung seiner Oberfläche erfährt. Für di e Blindsäcke hat Cuénot ausdrücklich festgestellt, dass sie an der Fettaufnahme participiren; man wird aber, wie v. Fürth ganz richtig bemerkt, schwerlich fehlgehen, wenn man überdies eine Betheiligung der Leberschläuche annimmt, zumal 
dieselben ja auch nichts weiter darstellen als Ausstülpungen des Mitteldarmes. Dernungeachtet stellen sich einem exacten Nachweis grosse Schwierigkeiten entgegen. Wie schon in der Einleitung erwähnt wurde, enthalten die reifen "Leberzellen" immer schon reichlich Fetttropfen, welche theils farblos, theils gefärbt erscheinen. Lereboullet bezeichnete sie daher bei Dekapoden direct als "Fett.. zellen", ebenso Frey und Leukart. Es genügt, einige frische Leberschläuche unter Zusatz von Krebsblut und geschützt vor Druck mikroskopisch zu untersuchen, um sich selbst an lange hungernden Thieren von dem ausserordentlich reichen Fettgebalt zu überzeugen. Ganz allgemein finden sich die kleinsten und spärlichsten Tröpfchen in der Spitze der einzelnen Schläuche, so dass dieselhe heller und durchsichtiger erscheint als die mehr basal gelegenen Theile. Dass es sich wirklich um Fett handelt, geht überzeugend aus dem Verhalten der Tropfen gegen Osmiumsäure, sowie gegen Alkohol und Aether hervor. Durch die erstere werden sie intensiv geschwärzt, während in Alkohol gehärtete und mit Aether extrahirte Leberstücke an Stelle der Tröpfchen Lücken (Vacuolen) erkennen lassen. Ich stehe nicht an, in dem so reichlich angehäuften Leberfett der Krebse Reservematerial zu erblicken, welches zum Theil den gleichen Ursprung haben dürfte wie etwa das Fett im Darmepithel eines in der Verdauung getödteten Wirbelthieres, zum anderen Theil aber vielleicht unabhängig von resorptiven Vorgängen in den Zellen gebildet wird. Für letztere Vermuthung würde der Umstand sprechen, dass es mir nicht gelungen ist, das Fett durch Hungern ganz zum Schwinden zu bringen. Indessen müssten derartige Versuche unter allen Umständen noch weiter ausgedehnt werden. Zwisehen den "Fettzellen" sieht man allenthalben grosse helle kugelige Blasen, welche in der Regel bräunlichgelbe Tropfen und Tröpfchen enthalten. Es sind dies die schon längst bekannten und schon von Max W eber als "F ermentzellen" bezeichneten Gebilde. Ohne allen Zweifel sind sie es, welche das specifische Secret der Drüse liefern und nicht die von demselben Autor "Leberzellen " benannten fetthaltigen Elemente ${ }^{1}$ ). W eber hält die Fetttröpfchen der letzteren für "Secrettröpfehen": was sicher gänzlich unzutreffend ist. $\mathrm{Zu}$ einer im Wesentlichen richtigen Auffassung ist dagegen Frenzel gelangt, welcher die

1) Camillo Schneider (Lehrb. d. vgl. Histologie 1902. Jena, G. Fischer) hält diese Elemente für „Excretzellen“, ohne jedoch diese Ansicht näher zu begrïnden (l. c. p. 491). 
Fettnatur der Tropfen abermals constatirte (vgl. Einleitung). Da es sich bei den grossen blasigen Zellen sicher um secernirende Elemente handelt, und zwar um solche, welche nicht nur "Fermente", sondern wahrscheinlich das ganze Secret liefern, so dürfte es sich empfehlen, sie nach Analogie der Bezeichnungen für die Schneckenleber als "Secretzellen", die fetthaltigen "Leberzellen" aber wegen ihrer unzweifelhaften resorptiven Function als "Resorptionszellen" zu bezeichnen. Man sieht leicht, dass es unter solehen Umständen nicht ganz leicht ist, Fettresorption seitens solcher Zellen nach Fütterung festzustellen.

Von der Annahme ausgehend, dass vielleicht Fett als solches unzersetzt aufogenommen wird, habe ich zunächst Versuche mit gefärbtem Olivenöl angestellt, welches in Lösungen von WittePepton emulgirt war, da Oel allein erfahrungsgemäss schlecht vertragen wird. Als Farbstoff fand ich Alcanna am besten geeignet. Die nach Ablauf von 4-5 Tagen dem Thier entnommenen Stücke des Mitteldarmes und der Drüse wurden in Müller-Formol conservirt und nach gewöhnlicher Weiterbehandlung mit $65-70 \%$ Alkohol in ein Gemisch von Gelatine, Gummi arab. und Glyeerin gebracht. Nach , 4-5 tägigem Verweilen in einem Thermostaten; werden die Objecte in einem Uhrschälchen mit der ganz dickfüssigen Mischung in Alkohol-Formol gebracht und wie Celloidinpräparate weiterbehandelt. Es gelang mir, die Angaben $\mathrm{Cu}$ énot's bezüglich der Fettaufnahme von Seiten des Mitteldarmes zu bestätigen, dagegen kam ich hinsichtlich der Mitteldarmdrüse auf diesem Wege zu keinem Resultat. Ein solcher Nachweis wäre nur dann leicht, wenn wirklich Fett als solches, d. h. unzersetzt, zur Resorption gelangte, denn dann wäre es ohne Zweifel möglich, die mit Alcanna gefärbten Tröpfchen in den Zellen neben den anderen zu erkennen. Er wird aber im gegebenen Falle sehr schwer oder ganz unmöglich, wenn,

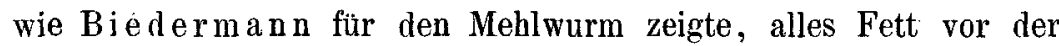
Resorption hydrolytiseh gespalten wird, so dass bei Fütterung gefärbten Fettes immer nur farblose Tropfen und Tröpfchen in den Zellen sich finden, welche die Resorption vermittelı. Ein Mehr oder Weniger von Fett in an sich fettreichen Zellen ist naturgemäss sehr schwer mit Sicherheit festzustellen. Demungeachtet habe ich mich, wie ich glaube, mit aller Bestimmtheit von dem Vorhandensein einer sehr ausgiebigen Fettresorption seitens. der Krebsleber überzeugen können. Berücksichtigt man die starke steatolytische Wirkung des Secretes, so wird 
man ja von vornherein kaum zweifeln können, dass neben anderen gelösten Nahrungsbestandtheilen auch die Componenten der Neutralfette in die Drüsenschläuche eindringen, um dort zur Resorption zu gelangen. Die Frage kann offenbar nur die sein, ob die Synthese der Fette schon in den "Resorptionszellen" oder erst irgendwo jenseits derselben stattfindet.

Füttert man einen gesunden lebhaften Krebs, der, wie stets, in fliessendem Wasser gehalten werden muss, mit einem dickflüssigen Brei aus Milchrahm und etwas Mehl in der schon beschriebenen Weise während 3-5 Tagen (täglich ein Mal), tödtet dann das Thier und untersucht kleine Stückchen der frischen Mitteldarmdrüse in Krebsblut, so zeigen sich die Schläuche auffallend stark fetthaltig. Niemals konnte ich Tröpfehen im Lumen der Drüsenschläuche mit Sicherheit erkennen, dagegen erweisen sich die Resorptionszellen ganz erfüllt mit Fetttropfen versehiedener Grösse. Zum Zwecke einer genaueren histologischen Untersuchung wurden ganz kleine Stücke der frischen Drüse in Flemming'sche Lösung gebracht nach gehörigem Auswaschen in Alkohol entwässert und, um eine weitere Lösung von Fett nach Möglichkeit zu vermeiden, einfach mit dem Rasirmesser geschnitten. Zum Vergleiche werden Drüsenstückchen von einem Hungerthier (3 Wochen ohne Nahrung) ganz ebenso behandelt. Bei der darauffolgenden Untersuchung dünner Schnitte ergaben sich so auffallende Unterschiede, dass auf den ersten Blick die dem Hungerthiere entsprechenden Schnitte durch den viel geringeren Gehalt an (geschwärzten) Fetttropfen erkennbar waren. Das Fett erschien in den Resorptionszellen stets vorwiegend in den basalen Abschnitten angehäuft.

Eine Thatsache, die sich vielleicht, abgesehen von dem Fettreichthum an sich, zu Gunsten der Annahme einer directen Fettaufnahme von Seiten der Krebsleber geltend machen liesse, scheint mir auch in der von Gérard untersuchten Zusammensetzung des Leberfettes einer von den Neu-Hebriden stammenden Landkrabbe (Birgus latro) gegeben zu sein. Es ergals sich nämlich, wie ich einem. Citate bei v. Fürth entnehme, dass dieses Fett hauptsächlich aus dem Glycerid der Laurinsäure $\left(\mathrm{C}_{12} \mathrm{H}_{24} \mathrm{O}_{2}\right)$ besteht. Daneben finden sich nur geringe Mengen von Stearinsäure, Palmitinsäure, Caprinsäure, Caprylsäure und anderen gesättigten und ungesättigten Fettsäuren in Form ihrer Glyceride. Die Nahrung von Birgus latro, dem sogenannten Palmendieb, besteht hauptsächlich aus Cocosnüsseu, welche dieser Krebs mit grossem Geschick 
aufzumachen weiss. Das Cocosfett besteht aus einem Gemenge von Glyceriden der Laurin-, Myristin-, Palmitin-, Capryl-, Caprin- und Capronsäure, und es liegt, wie v. Fürth bemerkt (1. c. S. 232), jedenfalls nahe, anzunehmen, dass die Zusammensetzung des Leberfettes in hohem Grade von der Besehaffenheit der Nahrung abhängig sei. Es scheint mir nun bei der nicht wegzuleugnenden resorptiven Function der Mitteldarmdrüse die natürlichste Annahme, dass jenes Nahrungsfett entweder als solches oder, wie es wohl wahrscheinlicher ist, nach vorausgehender hydrolytischer Spaltung direct in die Leber gelangt, um in den betreffenden Zellen abgelagert zu werden.

Bei den äusserst geringen Dimensionen des Mitteldarmes der Dekapoden einerseits, der enormen Oberfläche, welche dagegen die Leberschläuche darbieten, andererseits erscheint natürlich für die physiologische Bewerthung der resorptiven Function der Mitteldarmdrüse der sichere Nachweis von grösster Bedeutung, dass der lange Enddarm überhaupt nicht zu resorbiren vermag. St. Hilaire trug bei Flusskrebsen die obere Partie des Panzers im Bereich der Abdominalsegmente ab; dann wurde die über dem Darm verlaufende Aorta bei Seite geschoben, der abdominale Darmabschnitt mit einer Nadel umstochen, Pepton injicirt und abgebunden. Auch nach $6-8$ stündigem Verweilen des Peptons im Darme konnte ein Uebergang desselben in das Blut niemals constatirt werden, während dagegen eine Vesuvinlösung unter den gleichen Bedingungen mit Leichtigkeit in die Körperflüssigkeiten überging. Wurde der mit Pepton gefüllte und abgebundene Darm herausgeschnitten und in physiologische Kochsalzlösung gelegt, so führte er noch mehrere Stunden lang peristaltisehe Bewegungen aus. Doch auch nach 12 Stunden konnte kein Pepton in der umgebenden Flüssigkeit nachgewiesen werden; auch war das Pepton aus dem Inneren des Darmes nicht verschwunden.

Endlich wurde in Anlehnung an bekannte Versuche von F. Hofmeister ein Krebsdarm in kleine Stücke zerschnitten und 15-20 Stunden bei Zimmertemperatur oder 6-8 Stunden bei Brutofenwärme in einer peptonhaltigen, physiologischen Kochsalzlösung belassen. In keinem Falle konnte ein Verschwinden von Pepton beobachtet werden. St. Hilaire gelangte so schliesslich za der Ueberzeugung, dass wie für Farbstoffe so auch für die Eiweissverdauungsproducte nicht der Darm, sondern die Leber als Resorptionsorgan anzusehen sei.

Was zunächst die Versuche am herausgeschnittenen oder gar 
zerstückelten Enddarm anlangt, so wird man ihre Beweiskraft nicht allzu hoch einschätzen dürfen, denn es können hier ganz andere Verhältnisse vorliegen als bei Warmblütern (Säugethieren), und es scheint vor Allem auch die Beobachtungszeit zu kurz, um einigermaassen sichere Schlüsse $\mathrm{zu}$ ziehen, da wir erfahrungsgemäss wissen, dass Krebse auch bei normaler Fütterung nur langsam verdauen bezw. resorbiren. Wenigstens scheint dafür das verhältnissmässig späte Eindringen von Nahrungsbestandtheilen in die Leber $\mathrm{zu}$ sprechen, wie es Cuénot fand, und wie ich es auch selbst beobachtete. Ich habe mir viel Mühe gegeben, bei Krebsen die Ausführungsgänge der Mitteldarmdrüse zu unterbinden und dann nach „Fütterung“ (d. h. Injection per os) mit Lösungen von Witte-Pepton, wenn möglich, quantitativ, durch Bestimmung des N-Gehaltes, der Lösung der vorliegenden Frage näherzutreten, stiess aber auf so grosse technische Schwierigkeiten, dass ich den Plan aufgeben musste. Nur in einem einzigen Falle gelang es mir, beide Ausführungsgänge zu unterbinden und das Thier drei Tage am Leben zu erhalten. Es zeigte sich, dass der "Magen" noch fast Alles enthielt, was injicirt worden war, eine Resorption hier also nicht stattgefunden hatte. Dass aber auch der Enddarm innerhalb 24 Stunden nicht in merklichem Grade Pepton resorbirt, geht aus folgendem Versuche hervor. Einem Krebs wurde der Panzer dorsal zwischen Herz und Magen geöffnet und eine feine, gebogene Sonde unter den Darm geschoben, dieser gehoben und durch Auflegen der Sonde auf beide Wundränder festgestellt. Dicht hinter den beiden Ausführungsgängen der Mitteldarmdrüse wurde dann der Darm geöffnet, nach Einführung einer Canüle mit Leitungswasser ausgespritzt und schliesslich an beiden Seiten des Finschnittes fest abgebunden. Nach Verschluss der Wunde wurde dem Thiere per anum eine Peptonlösung von bekanntem N-Gehalt eingespritzt, der Darm am After umstochen und abgebunden. Bei Bestimmung des N-Gehaltes im Inhalte ergab sich nach 24 Stunden kein die Fehlergrenzen übersteigender Verlust.

Auf Grund aller im Vorstehenden mitgetheilten Thatsachen darf man wohl behaupten, dass die sogenannte "Leber" der Dekapoden wie jene der Schnecken physiologisch und morphologisch nichts weiter ist als der in Drüsenform umgestaltete Haupttheil des Mitteldarmes. Dem Mitteldarmrest kommt im Wesentlichen die gleiche Function zu wie der Drüse, wenigstens soweit es sich um Resorption handelt. 


\section{Die physiologische Morphologie des Pylorustheiles.}

Für die Schnecke (Helix pomatia) haben Biedermann und Moritz gezeigt, dass der Eintritt von Mageninbalt in die Mitteldarmdrüse mit mechanischer Nothwendigkeit durch gewisse anatomische Einrichtungen bedingt wird, welche sich in der Gegend der Einmündung der Drüsenausführungsgänge finden. Es lag nahe, auch beim Krebs nach solchen zu suchen, und es ist mir, wie ich glaube, gelungen, die sehr verwickelten anatomischen Verhältnisse der Pars pylorica des Krebsmagens mit ziemlicher Sicherheit physiologisch zu deuten.

Wohl die beste bisherige Darstellung der Anatomie des Kaumagens von Astacus fluviatilis hat Huxley in seinem trefflichen Buche „Der Krebs" gegeben (S. 45-52), und es darf hier wohl auf dieselbe, sowie die beigegebenen Abbildungen verwiesen werden. „Der Durchgang von der Cardiakammer zur Pförtnerkammer ist sehr eng. Ausser einer starken Querfalte beobachtet man an dieser Stelle auch noch ein konisches, mit zahlreichen Härchen bedecktes Zünglein, welches die an sich enge Oeffnung in die Pförtnerkammer noch mehr verengert. Uebrigens ist die Höhle der letzteren ebenfalls sehr eng; ihre nach innen gewölbten Wände sind ausserdem mit Haaren überzogen, so dass die Nahrungsstoffe durch diese Chitinborsten so zu sagen durchgeseiht werden und nur die feinsten Theile in den Darm eintreten können." (Vogt und Yung.) "In der hinteren Hälfte der Pyloricalkammer sind die Seitenwände gleichsam eingedrückt, und oben treten sie (Textfig. 1) in der Mittellinie so nahe an einander, dass nur ein senkrechter Spalt zwischen ibnen bleibt, der selbst noch wieder von Haaren durchkreuzt wird, die auf den beiden Wandflächen stehen. In der unteren Hälfte jedoch krümmt sich jede Seitenwand nach aussen und bildet eine kissenförmige, nach unten und innen blickende Fläche (Fig. 1). Wäre der Boden der Pyloricalkammer

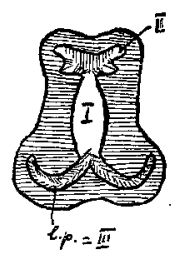

Fig. 1. Querschnitt dureh den Pylorusmagenn. Huxley. flach, so würde in ihrer unteren Hälfte ein weiter, dreieckiger Gang offen bleiben. Thatsächlich aber erhebt sich der Boden in der Mitte zu einer Leiste, während er sich an den Seiten der Gestalt der beiden kissenförmigen Flächen anpasst. Die Folge davon ist, dass die ganze Höhle des hinteren Theiles des Pyloricalabschnittes des Magens zu einer engen, dreischenkligen Spalte reducirt ist. Im Querschnitte ist der senkrechte 
Schenkel dieser Spalte gerade, während die beiden seitlichen nach oben concav sind (Fig. 1). Die Kissen der Seitenwände sind mit kurzen, dichtstehenden Haaren besetzt. Die entsprechenden Oberflächen des Bodens erheben sich zu parallelen Längswülsten, deren Kanten mit sebr feinen Haaren eingefasst sind. Da Alles, was aus dem Cardiasack in den Darm tritt, diesen eigenthumlichen Apparat durchsetzen muss, so kann nur die feinstrertheilte feste Materie durchschlüpen, solange die Wände geschlossen sind." (Huxley l. c.)

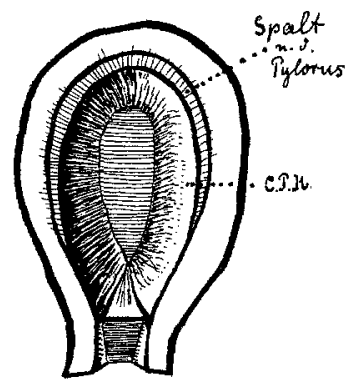

Fig. 2. Cardropyloricalklappe v. cer Cardia aus gesehen (Bezeichnungen wie in allen folgen-
den Figuren vgl. Tafolerklärung).

Ich habe den Pylorustheil bei einer ganzen Anzahl von Krebsmagen in Schnittserien zerlegt (Quer-, Horizontal- und Sagittalschnitte) und ausserdem nach entsprechender Härtung in verschiedenen Richtungen angeschnitten, z. Th. nach Injection mit farbigen Massen, um die oft nur schwer sichtbaren Communicationswege genauer festzustellen. Es gelingt so fast noch besser als durch das Studium von Serienschnitten, sich ein klares Bild des complicirten Baues zu machen. Nach ihrer physiologischen Bedeutung lassen sich an dem Pylorusabschnitt des Krebsmagens drei Haupträume unterscheiden:

1. Der Stauaparat.

2. Das Mitteldarmfilter.

3. Das Mitteldarmdrüsenfilter.

In der Textfigur 1 sind diese drei Räume durch die eingeschriebenen Zahlen kenntlich gemacht.

Betrachtet man den Längsdurchschnitt eines A st a cu s - Magens, wie ihn Huxley in seinem Buche S. 49 Fig. 10 darstellt, so erkennt man leicht, dass die Ansatzstelle des Pylorus an den Kaumagen durch eine grosse Falte, die Cardiopyloricalklappe, nahezu abgeschlossen wird. Wie die schematisirte Fig 2 zeigt, bleibt nur ein schmaler, spaltförmiger, mit Haaren besetzter Verbindungsweg übrig, der die Klappe als Halbkreis umzieht. $\mathrm{Er}$ führt in eine Art Vorraum (VR), welcher direct mit dem Stauapparat communicirt.

Er ist auf den folgenden Figuren mit $V R$ bezeichnet. Oben, d. h. entsprechend dem oberen Rand der Cardiopyloricalklappe, ist dieser Raum unpaar und führt direct in den Stauapparat (Taf. VII Fig. 10); mehr nach unten spaltet er sich rechts und links (Textfig. 3), 
indem das Gewebe der Klappe ihn theilt. Auch sehen wir, dass der Vorraum nun nicht mehr allein mit dem Stauraume communicirt, sondern dass rechts und links ein Eingang in das Drüsenfilter führt. Weiter nach unten versehliesst sich der Durebgang zwischen Cardia und Pylorus. Noch oberhalb der Communication mit dem Stauapparat, im Kuppeldache des Vorraumes, beginnt Apparat Nr. 2, Dieser aber bildet mit dem Stauapparat zu Beginn des Pylorus eine Einheit, während sich das Drüsenfilter schon merklich absetzt.

\section{Der Stauapparat.}

Verfolgt man nun die Quer- und Horizontalschnitte weiter in der Richtung nach dem Darme zu, so findet man vorab, dass im Centrum des Gebildes die Wände beginnen, eine starke Chitinisirung zu zeigen. Um es kurz zu machen: Der Canal führt zwischen zwei Platten hindurch, die ihm im Querschnitt eine ovale Gestalt geben. Die.Form der einzelnen Platte ergibt sich aus Taf. VII Fig. 10, die einen ganzen sagittal aufgeschnittenen Pylorus (im Schema) reproducirt. Man sieht, die Nahrung gelangt zuerst in einen recht ansehnlichen Raum, der sich jedoch in der Richtung nach dem Darme zu immer mehr verengt; zuletzt laufen die Platten in recht feine Spitzen aus, die zusammengelegt,

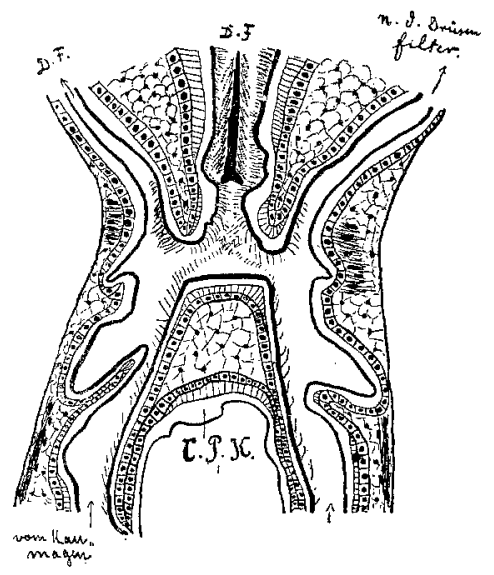

Fig. 3. Horizontalschnitt durch den Uebergangstheil von Cardia zum Pylorus unterhalb des Stauraumes. eine Art konisches Rohr bilden, das ein immer enger. werdendes Lumen besitzt, welch letzteres noch durch je zwei wechselweise übereinandergreifende Chitinsäume dicht gemacht wird. Es kann daher, was einmal in diesem Theil des Stauapparates sich befindet, diesen nicht anders verlassen als durch das reusenartig immer enger werdende Lumen. Die hierdurch bedingte kräftige Stauung wird noch dadurch verstärkt, dass der feine übrigbleibende Durehgang nicht in der Richtung des Nahrungsstromes liegt, sondern etwa um $45^{\circ}$ nach aufwärts gedreht, so dass jenem Strome vor Allem die einander übergreifenden Ränder beider Platten entgegentreten (Taf. VII Fig. 6 und 10). Dass in dem geschilderten Apparate die Staung wirklich E. Pflüger, Archiv für Physiologie. Bd. 101. 
eine kräftige sei, kann woch durch Folgendes bewiesen werden. Erstens beobachtet man, dass der Raum zwischen den beiden Platten, verglichen mit dem "Vorraum", einen festgepressten Inhalt hat. Ein mit in Peptonlösung suspendirtem Carminpulver gefüttertes Thier hat, wie wir sahen, zwei Kotharten; die eine kommt aus der Mitteldarmdrüse, die andere direct aus dem Stauapparat. Trotzdem aber nur wenig Carmin einer klaren Peptonlösung beigegeben wurde, so finden wir doch als "Darmkoth" eine beträchtlich dicke "Wurst", besser ein Stäbchen, welches aus den gröberen Carminkörnern zusammengepresst ist. Auch auf den Schnitten sehen wir, dass der Inhalt des Stauapparates fest zusammengeballt ist. Wir entnehmen hieraus schon, dass höchstwahrscheinlich die Aufgabe der beschriebenen Vorrichtung sein wird, alles Gelöste vom unverdauten Rückstande abzupressen. Hierzu aber lässt auch der histologische Bau der Pyloruswand die Platten sehr geeignet erscheinen. Es lassen sich daran vier Schichten unterscheiden: circuläre Muskelfasern (die äusserste), dann longitudinale Muskelfasern, Bindegewebe, und endlich Epithel mit dem dicken Chitinbesatz, der eigentlichen Platte. Schon die bedeutende Bindegewebsschicht lässt schliessen, dass das Ganze einen starken Druck auszuhalten habe. Das Wichtigste aber ist die unverhältnissmässige Dicke des Chitinbelages. Dieser besteht aus zwei Schichten, einer nach aussen gelegenen stark färbbaren (Säurecarmin) Faserschicht und einer nach dem Lumen zu liegenden wenig gefärbten. Die in allen meinen Präparaten deutliche Schicht zwischen Epithel und Platte (auch an anderen Stellen) könnte wohl auch als Vorrichtung, einem Drucke Widerstand zu leisten, gedeutet werden, wenn es sich nachweisen liesse, dass wir es nicht mit einem "Kunstproducte" zu thun haben; die wohlentwickelte Muskulatur aber zeigt, dass es sich nicht nur um einen passiven Widerstand handelt, sondern um einen activ ausgeübten Druck. Der Eintritt in den Stauraum ist relativ frei, d. h. die sich davorstellenden Haare sind viel weniger zahlreich als bei den unten zu besprechenden Filterapparaten.

Die oben erwähnte reusenartige Spitze nun mündet genau in ein freies Chitinrohr, welches dorsal und zwar da an der Pyloruswand angewachsen ist, wo diese in die vordere Wand des Coecum übergeht. (Taf. VII Fig. $10 T$.) Dieses Rohr, welches durch einen Längsspalt zeigt, dass es nichts ist, als eine röhrenförmig gebogene Chitinplatte, ist gerade so lang, dass es die aus dem Stauapparate kommenden 
festen Pressrückstände direct in den chitinisirten Enddarm leitet, so dass der Mitteldarm nicht von ihnen verletzt werden kann. Dieses Rohr nun ist die sogenannte dorsale Pylorusklappe, die nicht, wie $\mathrm{Huxley}$ meinte, das sehr wohl mögliche Rückstauen verhindern soll, sondern anderen Zwecken dient. Cuénot nannte sie "Cornet pylorique". Ich werde sie im Folgenden als "Trichter" bezeichnen, nach Analogie des Gebildes, welches von Schneider u. A. bei gewissen Arthropoden, die sich von festen Substanzen nähren (Insecten, Julus), so genannt wurde. „Si l'on dissèque un animal en pleine digestion, on constate, que les matières solides non digérées s'engagent toutes dans le cornet, comme l'a déjà remarqué Frenzel, et tombent dans l'intestin terminal; les graisses fluides et les liquides filant seuls dans l'intestin moyen, dont l'épithélium délicat est ainsi garanti contre de trop rudes contacts. Il est compréhensible que le.cornet de l'Écrevisse ne se prolonge pas jusqu'aux environs de l'anus, comme le ,Trichter' des Insectes, puisque l'intestin terminal est revêtu d'une épaisse cuticule. Je pense que le cornet pylorique a le même rôle chez les types à intestin moyen très court (Palinurus, Galathea), mais chez ceux où il est long (Pagurus, Caridides, Brachyures), il n'ya rien de semblable: le cornet pylorique, quand il existe. laisse les aliments s'engager directement dans l'intestin moyen." (Cuénot.) Die Reuse, sowie deren Zusammenhang mit dem Trichter, war $\mathrm{Cu}$ énot nicht bekannt.

\section{Das Mitteldarmfilter.}

Wir haben bis jetzt den Stauraum ganz für sich betrachtet, als stünde er ausser mit dem Kaumagen und Darm mit nichts in Communication; dem ist aber nicht so. Beide Platten schliessen weder oben noch unten dicht auf einander. Nach oben haben sie saumartige Ränder, die den Durchgang nach dem darüber gelegenen Raum zwar gestatten, aber sehr einengen; ein dichter Haarbesatz hält alle gröberen Bestandtheile zurück. So gelangt eine fast körnerfreie Nahrung in den über den Platten befindlichen Raum. Dieser ist in der Nähe des Kaumagens die e infache Fortsetzung des Vorraumes, senkt sich aber mehr nach der Mitte des Pylorus zu herab, rechts und links vom Stauapparat, und umgibt diesen sattelförmig (siehe Taf. VII Fig. 3 und 4). Dieser Raum mit seinen Schutzvorrichtungen ist nun das, was ich Mitteldarmfilter genannt habe. In ihn führt der Weg aus dem Vorraum eben durch 
einen einfachen Canal, der stark mit Haaren besetzt ist. Nach dem Darm zu wird der mediane Theil des Filterraumes immer unbedeutender, (vgl. Taf. VII Fig. 3 und 4, sowie Textfigur 4), bis zum Verschwinden, während die Seitentheile, als zwei getrennte Röhren, schliesslich ihren Inhalt in den Mitteldarm, seitlich vom "Trichter", ergiessen. (Taf. VII Fig. 6.)

So haben wir hier schon einen ganz ungemein zweckmässig eingerichteten Apparat, dessen Function es ist, die dem zarten resorbirenden Epihel des Mitteldarmes (und, wie wir gleich sehen werden, auch der Mitteldarmdrüse) gefährlichen gröberen Körner direct dem Trichter und somit dem chitinisirten Enddarm zu übergeben, während durch das Filter de facto nur ganz fein vertheilte Nahrung in den resorbirenden Mitteldarm gelangt (siehe die betreffenden Figuren).

\section{Das Mitteldarmdrüsenfilter.}

Wir kommen nun zu einer Vorrichtung, die an Feinheit und Complication kaum ihres Gleichen hat. Sehen wir daneben das einfache Mitteldarmfilter, so können wir ohne Weiteres schon sagen, dass diesem letzteren im Verhältniss nur eine geringe Rolle zukommen muss. Wie wir sahen, hat dieses den Mitteldarm, jenes aber - das zeige ich noch - die Mittelilarm drüse zu schützen und ihr filtrirte Nahrung zuzuführen. In Anbetracht der durch ihren Umfang bedingten wesentlich grösseren Bedeutung der Mitteldarmdrüse, mit dem Mitteldarme verglichen, versteht sich das angedeutete ungleiche Verhältniss beider Filter von selbst. Noch mehr: eine Verletzung der Mitteldarmzellen ist wohl möglich, doch nicht so leicht eine Perforation des immerhin starken Mitteldarmes. Anders in den zarten Schläuchen der Drüse, deren Verletzlichkeit von Jedem wohl gekannt und gefürchtet wird, der mit Astacus operativ arbeitet, und deren Perforation vor Allem eine unbedingte Todesursache für das Thier ist.

Ich will nun die Beschreibung versuchen. Die Haupttheile des Apparates sind, wie ich das schon andeutete, in jenen paarigen Ausbuchtungen an der Basis des Pylorustheiles untergebracht, welche als "Seitenzähne" bezeichnet werden, und die demnach unterhalb des Stauapparates liegen (Texfigur 1 III). Sie bieten im Wesentlichen je einem Spaite Raum, der als soleher im Vorraum beginnt (Textfigur 3; Taf. VII Fig. 10) und stets mit dem medianen Theil desselben (dem vorderen Stauraume) in Verbindung bleibt. Die Wände dieses Spaltes sind nicht eben, sondern stark nach aussen gekrümmt, 
was durch die sogenannte "kissenförmige Fläche" bedingt wird, um die sie sich legen (vgl. die Querschnitte). Schon die feine, mit vielen starken Haaren besetzte Communication mit dem Vorraume und dem Stauraume, sowie die stete dichte Behaarung der Innenwände deutet uns an, dass wir es auch hier mit einem Filterraume zu thun haben, ähnlich dem Mitteldarmfilter. Das würde sich auch schon aus Huxley's Fig. 9E (unserer Textfigur 1) ergeben. Doch von diesem Querschnitte aus nach hinten gerechnet werden die Verhältnisse ganz anders. Sehen wir uns einen Querschnitt an (Taf. VII Fig. 3): Was hier zuerst auffällt, ist eine seltsame An. ordnung des Inbaltes im Stauapparate. Schon vor dem Bereiche des Schnittes, den Textfigur 4 wiedergibt, beginnt unten seitlich in den Stauplatten je eine Rinne sich kenntlich zu machen, die, je mehr wir uns dem Darme nähern, um so grösser wird -(Taf. VII Fig. 3) und zuletzt sich nach

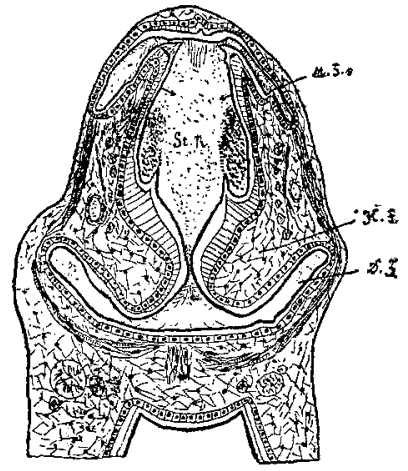

Fig. 4. Quersehnitt durch den Pylorustheil. Mitteldarmfilter, Rinnen in den Stauplatten vor Beginn des eigentichen Drüsenfilters. unten öffnet in die zu beschreibende Vorrichtung hinein, und zwar etwa da, wo diese beginnt. Später hört diese Rinne auf, nachdem sie erst ihre compacten Ränder verloren hat, an deren Stelle Haare treten. Doch ihr Zweek ist erreicht. Dieser wäre an sich schwer zu errathen, fände sich nicht in der Rinne eine fest zusammengepresste Masse, während der übrige Stauraum nur mit locker gelagerten Körpern gefüllt ist. Kein Zweifel: durch den Druck der Platten wird eine möglichst grosse Nahrungsmenge in die Rinne gedrückt, wobei natürlich ganz besonders gut der eigentliche Zweck erreicht wird: das Abpressen des Gelösten vom Rückstand. Später, wo die Rinne aufhört, dauert die scharfe Scheidung zwischen Gepresstem und Lockerem noch fort (Taf. VII Fig. 4), doch verschwindet sie in meinen Präparaten wieder, so dass nach dem Darm zu auch das locker Bleibende zu seinem Rechte kommt. Dergleichen ist bei dem Mitteldarmfilter nicht zu sehen. Sicherlich findet nach diesem zu kein erheblicher Druck statt, - ein Beweis dafür, wie wenig wichtig im Verhältniss die Resorption des Mitteldarmes ist. Wie nun der Druck ausgeübt wird, der jene auffallende Differenz der Consistenz des Staurauminhaltes bedingt, ist nicht ganz klar. 
Ich vermuthe Folgendes: Der Querschnitt der Platten ist an dieser Stelle eiförmig (Textfigur 4; auch Taf. VII Fig. 3), d. h. oben spitz zulaufend, unten breit. Oben zwischen den beiden beschriebenen Säumen ist auch der meiste Spielraum. Kurz, ich denke mir: wenn die an dieser Stelle mächtig entwickelte "circuläre" Muskulatur das ganze Gebilde einengt, werden die beiden schräg zulaufenden Platten oben in der Pfeilrichtung (Textfigur 4) einen Druck ausüben, und die Rinnen werden die Hauptmasse der nachgebenden Nahrung aufzunehmen haben. - Das eigentliche Drüsenfilter besteht, wie gesagt, aus zwei Spalten; das Gewebe zwischen ihnen bildet in Querschnitt eine unter spitzem Winkel oben scharf zulaufende Säule, ist in Wirklichkeit also eine scharfkantige Leiste (vgl. Querschnitte Taf. VII Fig. 3-5).

Verfolgen wir dieselbe von ihrem ersten Auftreten nach dem Darm zu, so finden wir sie zuerst gleich den Wandungen der Spalte stark behaart (Textfigur 1). Der Filterraum communicirt also hier mit dem Stauraum durch je einen feinen Spalt, dessen Ränder so dicht mit Haaren bewachsen sind, dass der zudringenden Nahrung eine wahre Phalanx entgegensteht, und zahlreiche in dieser hängengebliebene Körperchen geben Zeugniss von ihrer Wirksamkeit (Taf. VII Fig. 3). Weiter nach dem Darm zu ändert sich das Bild (Taf. VII Fig. 4): Die convexe (äussere) Wand der beiden Spalten oder Filterkammern bleibt in derselben Weise einfach behaart und schützt auch nach wie vor den Filterraum an seiner Communication mit dem Stauraum durch dichte Haarbüschel. Jedoch die den Filterkammern zugekehrten Wände der Leiste, sowie die concave innere Wand der Spalte selbst - beide gehen in einander über - beginnen ein ganz eigenthümliches Chitingebilde aufzuweisen, dem, wie mir hoffentlich $\mathrm{zu}$ zeigen gelingen wird, die Hauptthätigkeit im Filtriren der für die Mitteldarmdrüse bestimmten Nahrung zufällt. Betrachten wir uns vorab das Gebilde an unserem Querschnitte (Taf. VII Fig. 4), so sehen wir in regelmässigen Abständen radial (die Wand als Halbkreis gedacht) starke Säulchen in die Filterkammer ragen. Am Ende dieser Säulchen befinden sich starke, spitze Haare, und zwar so, dass jeweils das Haar der einen Säule über die vorhergehende Säule hinwegragt (vom Stauraum aus gerechnet), sie sich also alle dachziegelartig decken, doch so, dass eine feine Passage in das Innere des von zwei Säulchen gebildeten Viereckes freibleibt. Die Haare sind gegen den aus dem Stauraume kommenden Strom gerichtet, so 
dass das Feinste vom Feinen dieses Stromes in die kleinen Räume gelangen kann, ja, wegen der Vollständigkeit dieses Haarbesatzes sogar gelangen muss. Denn bei Injectionspräparaten fand sich blaue Gelatine fast nur in den Räumen, und alle Räume waren voll. Diese uns im Querschnitte als Säulchen erscheinenden Gebilde sind jedoch in Wirklichkeit lange Leisten, zwischen denen sich also Rinnen befinden, deren Richtung etwa parallel der Achse des Thieres verläuft (Textfigur 5). Die oben geschilderten Haare stehen kammartig ungemein dicht, so dass sie bis auf jenen feinen freibleibenden Fangspalt die Rinne fast oder ganz abschliessen. Wir können also mit Recht sagen: die Filterkammern baben doppelten Boden, einen unteren, festen, und einen oberen, aus dichten Haarkämmen bestehenden, durchlässigen. Dieser letztere nun ist das ejgentliche Filter. Der Raum zwischen den beiden Böden wird durch die Leisten in Rinnen, besser Röhren getheilt. Ueber den feineren Bau des Chitingebildes ist Folgendes zu sagen: Die Grundmembran besteht aus drei Chitinschichten: einer feinen äusseren, faserigen Schicht, einer homogenen und einer inneren, stärkeren Faserschicht. Fig. 5. Schema der AnordDie Fasern der äusseren Schicht verlaufen peri-

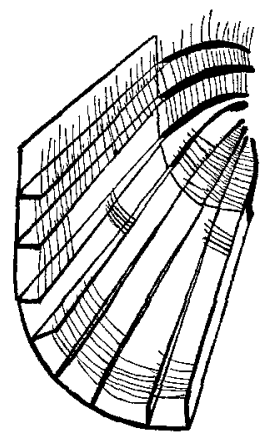
pherisch - der Querschnitt als Kreis gedacht -, die der inneren Schicht im Princip auch; jedoch bildet in jeder Rinne der Boden einen halben Cylindermantel, also im Schnitt einen Halbkreis. Die Leisten setzen im Querschnitte breit auf der Grundmembran an, laufen schmal zu und enden mit einer vogelkopfähnlichen Verdickung, die den Kamm trägt; reconstruirt würden die Leisten wie sehr schmale, relativ hohe Eisenbahnschienen aussehen. Vom Ansatzpunkte der Leisten verlaufen durch die homogene Schicht der Grundmembran schräge Faserzüge von der inneren zur äusseren Schicht, nicht ganz parallel den Kammhaaren; ihnen fällt sicher eine besondere mechanische Function zu. Augenscheinlich setzen sie sich in die Leisten fort; ob sie die "Fanghaare" bilden, weiss ich nicht.

Wo führen nun diese Röhren hin? Hierüber gaben mir Sagittalschnitte die erste Auskunft. Taf. VII Fig. 8 und 9 stellen zwei solche Schnitte dar, und zwar liegt die getroffene Stelle bei Fig. 8 etwas seitlich von der Medianebene, bei Fig. 9 noch näher zu dieser. Da unsere Röhren nicht genau longitudinal, sondern schräg verlaufen, 
so sind deren auch mehrere durchschnitten. Wir sehen aus den Figuren, dass nach dem Darm zu die Leisten sich von ihrer Unterlage abbeben. Sie biegen sich der "kissenförmigen" Fläche zu und bilden so ein korbförmiges, paariges Sieb, welches, noch verdichtet durch die Kammhaare, die Filterkammer vollständig abschliesst. Dieser Abschluss erfolgt gegen einen Raum, den ich die (Mitteldarm-) Drüsenvorkammer nennen will, und dessen Wände durch die Unterlage der Leisten gebildet werden, von der sich diese eben abgehoben haben. Was ich da versucht habe $\mathrm{zu}$ beschreiben, wird man, denke ich, ohne grosse Mühe aus den genannten Figuren, sowie dem Schema Fig. 10 reconstruiren können. Ich habe mich bemüht, in Taf. VII Fig. 7 einen Schnitt darzustellen, der recht deutlich zeigt, wie die die Röhren bildenden Leisten, eine Curve beschreibend, über einander verlaufen, und wie sie vorn einen aus Stäben zusammengesetzten Korb bilden. Taf. VII Fig. 5 zeigt sehr deutlich an einem Querschnitte, wie sich die Filterkammer gegen die Drüsenvorkammer absehliesst, und wie der Abschluss durch die feinen Kammhaare noch mehr gesichert wird. Sollten Körper in die Filterkammer gedrungen sein, ohne dass sie fein genug wären, um auch in die Filterröhren zu gelangen, so existirt für diese ein Ausweg in den Darm, den Taf. VII Fig. 9 und 10 zeigen. Ueber seine Gestalt kann ich nicht viel sagen, da er sich nur in Sagittalschnitten nachweisen liess.

\section{Die Drüsenvorkammer.}

Da, wo sich die Leisten, welche die uns bekannten „Röhren“ bilden, von ihrer Unterlage abheben, ergiesst sich - wie natürlich der filtrirte Inhalt jener Röhren in den durch die Unterlage gebildeten Raum: die D rüsenv orkammer (Taf. VII Fig. 9). Dieser Raum nun communicirt mit dem Darm nur durch einen feinen Spalt, der zur Ausstossung des in der Drüse nicht Resorbirten dient, und dessen Enge verhindert, dass das frische Filtrat etwa ohne Weiteres in den Darm übertritt. Dagegen wird dasselbe von den trichterförmigen, grossen Ansätzen der Mitteldarmdrüse aufgenommen. Gebildet werden die Wände jenes Spaltes je durch die kissenförmige Fläche und einen zungenförmigen Fortsatz $(Z F)$ der grossen Mittelleiste im Filterapparat einerseits und von einer Einstülpung der Wand der Drüsenvorkammer andererseits $(V)$, welche letztere in der Medianebene noch durch einen Chitinzapfen verstärkt wird. Der „zungenförmige 
Fortsatz" nun ragt so weit in den Darm und lässt zwischen sich und jener Einstülpung eine so schmale Passage, dass vornehmlich er es ist, der der Vorkammer den nöthigen Abschluss verleiht. Jener Fortsatz ist übrigens sicher eine der fünf Klappen, von denen Huxley Seite 52 spricht. Die oben angedeuteten Verhältnisse erhellen am besten aus Tafel VII Figur 8 (mehr seitlich), 9 und 10. Textfigur 6 stellt einen Horizontalschnitt dar, welcher sehr deutlich zeigt, in welcher Weise die Drüsenvorkammer mit der Mitteldarmdrüse zusammenhängt und wie ein wahrer Fangtrichter das aus dem Magen kommende Filtrat aufnimmt und nach der Drüse führt. Man sieht, wie die Drüsenvorkammer ein abgeschlossener Raum ist, der hier einer Stelle entspricht, die etwa zwischen Tafel VII Figur 6 und 7 zu liegen käme. Es ist fast nicht möglich, durch Worte oder Abbildungen zu zeigen, wie sehr die Nahrung g ezwungen ist, in diesen Drüsentrichter einzutreten, so deutlich wenigstens als dies aus dem natürlichen Präparat zu erkennen ist.

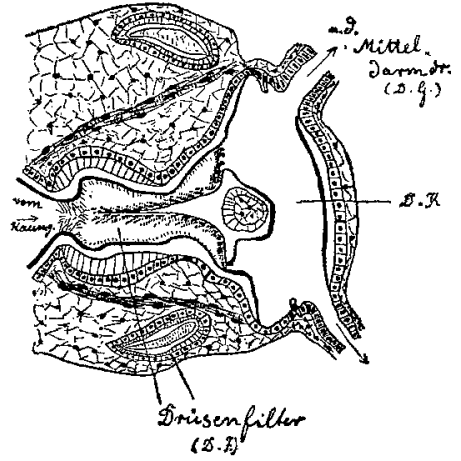

Fig. 6. Theil eines HorizontaIsehnittes durch den Pylorustheil. Verbindung zwischen Drüsenvorkammer $(D K)$ a. Mitteldarmdrüse. Dagegen ist folgender Versuch sehr instructiv. Ich konnte bei einer Injection feststellen, dass, ehe noch die blaue Masse in den Darm tritt, bereits ein wahrer Strahl aus den Löchern strömte, die durch das Entfernen der Drüsen entstanden sind. - Ob es mir im Vorstehenden gelungen ist, eine erschöpfende und hinreichend klare Beschreibung dieser ganzen Vorrichtung zu geben, weiss ich nicht, hoffe indess bestimmt, dass Dasjenige, was dem Leser zu vergegenwärtigen das Wort ungenügend war, die beigegebenen Abbildungen klar werden machen können. Jedenfalls ist es Thatsache, dass durch einen ganz ungemein complicirten und feinen Apparat die von der im Kaumagen ángedauten Nahrung abgepresste Flüssigkeit filtrirt und gezwungen wird, in die Mitteldarmdrüse zu gelangen, wo sje resorbirt wird. Dem von uns beschriebenen Siebe ist es auch wobl zuzuschreiben, dass der aus der D r üse kommende, stets feste Koth nicht in den Magen zurückgelangt, sondern in den Darm entleert wird. 
In der Abhandlung von G. Sta mati findet sich auch die Angabe, dass beim Krebse alle gröberen Partikel, welche der Zerkleinerung im Kaumagen nicht zugänglich und unverdaulich sind, durch den Mund nach aussen entleert werden. "Un phénomène assez curieux à constater dans l'histoire de la digestion chez l'écrevisse, e'est que toutes les parties alimentaires, que l'appareil masticateur stomacal est incapable de broyer sont rejetées au dehors par la bouche. Afin d'observer ce fait on soumet l'écrevisse à un régime végétal, par exemple des herbes ou des feuilles de végétaux qui contiennent du tissu ligneux. Après qu'elle a engéré ces substances, on constate que toutes les parties ligneuses sont rejetées par la bouche, comme si l'animal les vomissait."

Auch diese Erscheinung erklärt sich leicht aus dem ganzen Bau des Magens, welcher nur die allerfeinsten festen Partikel passiren lässt.

So dürfte denn der Verdauungsapparat des Krebses ein sehr lehrreiches Beispiel liefern für die befruchtende Wirkung, welche die Morphologie durch die gleichartige Berücksichtigung der physiologischen Function erfährt, und wie erspriesslich ein Zusammenwirken von Morphologie und Physiologie für die wirkliche Erkenntniss der Bedeutung eines Organes sich immer erweist.

Die vorliegende Arbeit wurde im physiologischen Institut zu Jena begonnen, im Leipziger zoologischen Institut fortgesetzt und im Züricher abgeschlossen. Den Herren Institutsvorständen und Assistenten spreche ich hiermit meinen verbindlichsten Dank aus.

\section{Literaturverzeichniss.}

1) Bartseh, Ueber Ernährungs- und Verdaungsorgane des Astacus leptodactylus. Budapester naturhistor. Hefte Bd. 2. 1878.

2) M. Braun, Ueber die histologischen Vorgänge bei der Häutung von Astacus fluviatilis. Arb. a. d. zool.-zootom. Inst. in Würzburg Bd. 2. 1875.

3) Biedermann und Moritz, Beiträge zur vergleichenden Physiologie der Verdauung. II and III. Pflüger's Archiv Bd. 73 und 75.

4) Claus, Zur Kenntniss des Banes und der Entwicklung von Branchipus und A pus etc. Gesellsch. d. Wissensch. Bd. 18. Göttingen 1873.

כ) Cuénot, Sur la physiologie de l'écrevisse. Compt. rend. Acad. Sc. Pariș t. 116 p. 1257. 1893. 
Cuénot, Etudes physiologiques sur les crustacées décapodes. Arch. de Bíol. t. 13.1895 .

6) Joh. Frenzel, Ueber die Mitteldarmdrüse der Crustaceen. Mitth. d. zool. Station zu Neapel Bd. 5. 1884.

Joh. Frenzel, Ueber den Darmcanal der Crustaceen. Arch. f. mikr. Anat. Bd. 25. 1885.

7) L. Frédéricq, Sur la digestion des albuminoides chez quelques invertébrés. Compt. rend. Acad. R. Belgique t. 46. 1878.

8) Frey und Leukart, Lehrbuch der Anatomie wirbelloser Thiere. 1847.

9) Gerstaecker und A. E. Ortmann, Crustacea II, in Bronn, Classen and Ordnungen Bd. 5 Abth. 2. 1901.

10) T. H. Huxley, Der Krebs. Internat. wissensch. Bibliothek Bd. 48. Brockhaus, Leipzig 1881.

11) Hoppe-Seyler, Ueber Unterschiede im chemischen Bau und der Verdaung höherer und niederer Thiere. Pflüger's Archiv Bd. 14. 1876.

12) F. W. Krukenberg, Zur Verdaung bei den Krebsen. Heidelberger Unters. Bd. 1 S. 331, Bd. 2 S. 261 und S. 23.1878.

13) Lereboullet, Mémoire sur la structure intime du foie. Paris 1853.

14) Lindner, Nonnulla de hepate et bile evertebratorum. Dissert. Berolini 1844.

15) Paul Mayer, Die Caprelliden des Golfes ron Neapel. Fauna und Flora des Golfes von Neapel. Leipzig 1882.

16) Mecke1, Mikrographie einiger Drüsenapparate der niederen Thiere. Müller's Arch. 1846.

17) Mac Munn, On the gastric gland of Mollusca and Decapod. Crustacea: its structure and functions. Phil. transact. R. Soc. vol. 193 p. 1-34. 1900.

18) F. Mocquard, Recherches anatomiques sur l'estomac des Crustacées podophthalmaires. Ann. Sc. nat. (6) Zool. t. 16. 1883.

19) Th. Fr. W. Schlemm, De hepate ac bile Crustaceorum et Molluscorum quorundam. Dissert. Berolini 1844.

20) C. de Saint-Hilaire, Sur la résorption chez l'écrevisse. Bull. Acad. Sc. de Belgique (3) t. 24 p. 506.1892.

21) Grégoire Stamati, Les phénomènes mécaniques, chimiques et physiologiques de la digestion chez l'écrevisse. Arch. soc. stünt. si lit. diu Jaši t. 3.

22) Max Weber, Ueber den Bau und die Thätigkeit der sogen. Leber der Crustaceen. Arch. f. mikr. Anat. Bd. 17. 1880.

23) A. V. Vitzon, Recherches sur la structure et la formation des téguments chez les Crustacées décapodes. Arch. de Zool. expér. vol. 10. 1882.

24) J. J. Parker, On the stomach of the freshwater Crayfish. Journ. of Anat. and Physiol. 1876.

25) F. Albert, Das Kaugerüst der Dekapoden. Zeitschr. f. wissensch. Zool. Bd. 39 S. 444. 


\section{Tafelerklärung.}

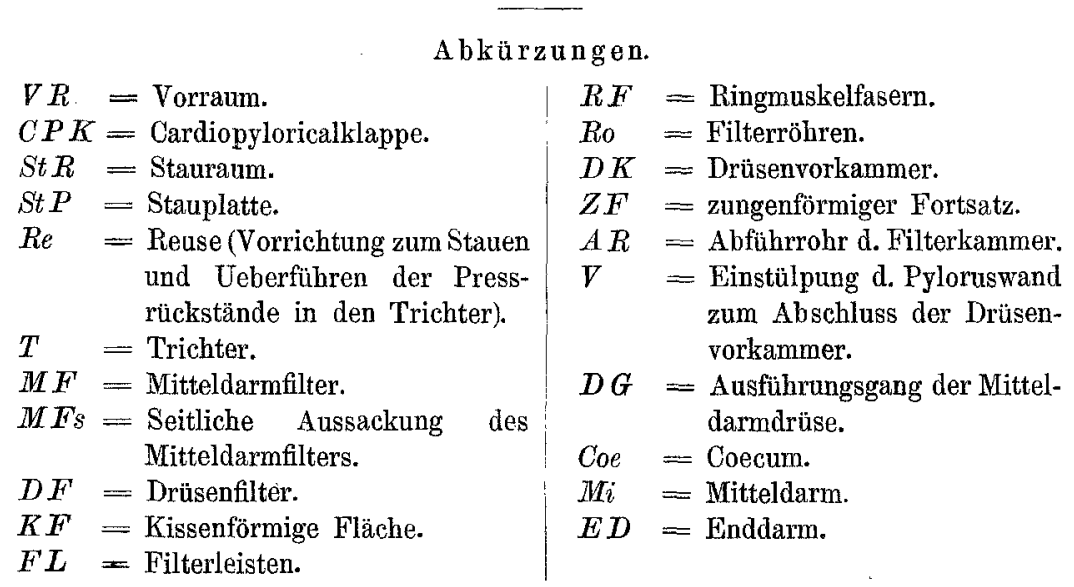

T a fel VII.

Fig. 1. Stück der Mitteldarmdrüse eines mit Carmin gefütterten Krebses.

Fig. 2. Schnitt durch die Drüse desselben Thieres.

Fig. 3. Querschnitt durch den Pylorustheil.

Fig. 4. Querschnitt durch den Pylorustheil weiter nach dem Darm zu.

Fig. 5. Rechte Seite eines Querschnittes noch weiter darmwärts an der Stelle, wo das Drüsenfilter siebförmig die Filterkammer gegen die Drüsenvorkammer abschliesst.

Fig. 6. Oberer Horizontalschnitt durch den Pylorustheil, um die Mündung des Mitteldarmfilters und die Lage von Rense and Trichter zu zeigen.

Fig. 7. Unterer Horizontalschnitt (Drüsenfilter).

Fig. 8. Sagittalschnitt durch den Pylorustheil.

Fig. 9. Theil eines mehr median geführten Sagittalschnittes (Drüsenfilter und Drüsenvorkammer zeigend).

Fig. 10. Schematische Darstellung eines ganzen, sagittal durchschnittenen Pylorustheiles aIs Uebersichtspräparat.

Alle Figuren, Tafel VII Fig. 1 u. 2 ausgenommen, vom Verfasser gezeichnet.

Sämmtliche Schnitte sind nach Härtung imit Alkohol oder Sublimat gewonnen und mit Säurecarmin nach P. Mayer gefärbt worden. Die Schnittdicke betrug durchschnittlich $10 \mu$. Sehr gute Orientirungspräparate erzielte ich auch durch Behandlung von Pylorusmagen des Krebses nach der bekannten TerpentinTrockenmethode (Härtung in Alkohol, dann Terpentinöl und Trocknen). Solche Präparate werden dann in verschiedenen Richtungen angeschnitten und mit der Lupe untersucht.

Vortreffliche Uebersichtspräparate liefert auch noch die folgende Methode: Die gehärteten Objecte werden in der von mir (Ueber die Anwendung von Celloidin in Mischung mit Cedernholzöl. Zeitschr. f. wissensch. Mikroskopie Bd. 17 S. 191. 1900) angegebenen Weise in Cedernöl-Celloidin eingebettet (wenige Tage), und mit Paraffin durchtränkt. Die Blöcke werden dann mit dem Mikrotom in Schnitte von etwa $1 / 2 \mathrm{~mm}$ Dicke zerlegt und wie gewöhnlich mit Eiweiss und Wasser aufgeklebt. Nach gutem Antrocknen wird das Paraffin und Celloidin abgelöst und die Objectträger auf 1-2 Tage in Terpentinöl gebracht, worauf man trocknen lässt. 


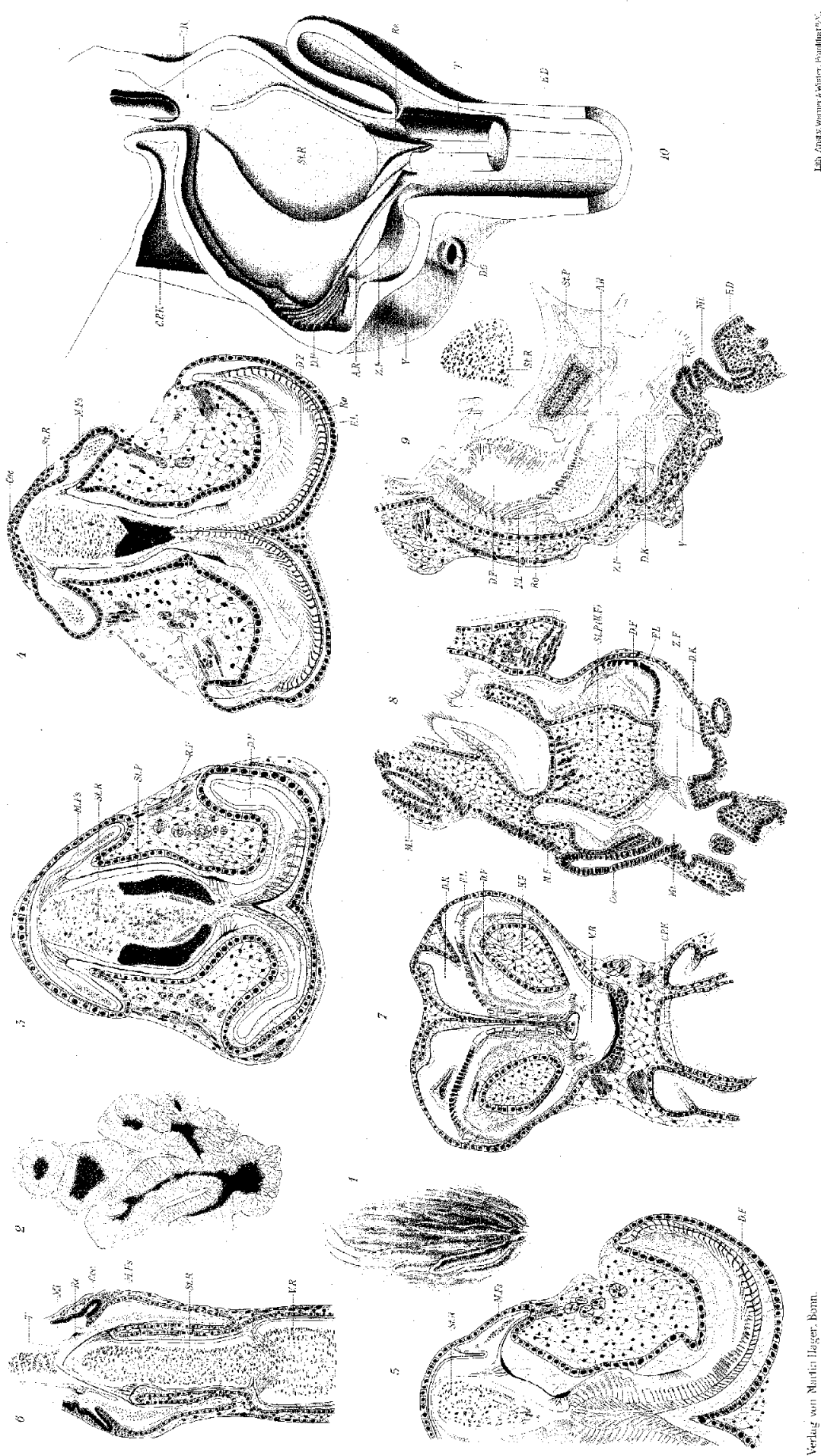

